\title{
Comunicación política y Covid-19. Estrategias del Gobierno de España
}

\section{Political communication and Covid-19: strategies of the Government of Spain}

\author{
Antonio Castillo-Esparcia; Ana-Belén Fernández-Souto; Iván Puentes-Rivera
}

Cómo citar este artículo:

Castillo-Esparcia, Antonio; Fernández-Souto, Ana-Belén; Puentes-Rivera, Iván (2020). “Comunicación política y Covid-19. Estrategias del Gobierno de España". Profesional de la información, v. 29, n. 4, e290419.

https://doi.org/10.3145/epi.2020.jul.19

Artículo recibido el 14-05-2020 Aceptación definitiva: 22-05-2020

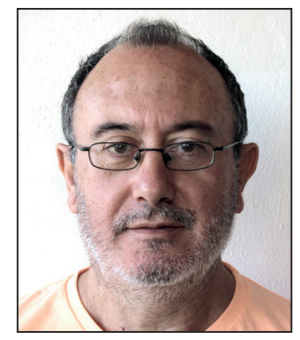

Antonio Castillo-Esparcia https://orcid.org/0000-0002-9751-8628

Universidad de Málaga Facultad de Comunicación e Instituto de Investigación en Relaciones Públicas Campus de Teatinos, s/n. 29071 Málaga, España acastilloe@uma.es

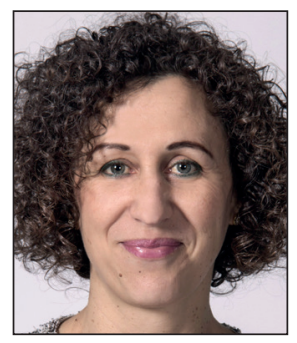
Ana-Belén Fernández-Souto https://orcid.org/0000-0003-2685-0604

Universidad de Vigo

Facultad de Ciencias Sociales y de la Comunicación Campus A Xunqueira s/n. 36005 Pontevedra, España abfsouto@uvigo.es

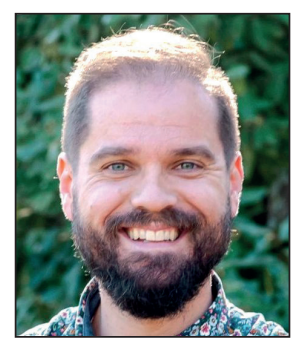
Iván Puentes-Rivera $\square$
https://orcid.org/0000-0003-1982-0984
Universidad de A Coruña
Facultad de Ciencias de la Comunicación
Campus de Elviña, s/n.
15071 A Coruña, España
ivanpuentes@uvigo.es

\section{Resumen}

La pandemia de la Covid-19 ha irrumpido de modo abrupto en las sociedades, con implicaciones sanitarias, económicas, políticas y comunicativas. Los gobiernos han tenido que planificar y aplicar de manera inmediata estrategias de comunicación para explicar las medidas que se han adoptado y para gestionar campañas de salud pública. Esta investigación analiza la estrategia de comunicación del Gobierno de España en el ámbito nacional e internacional desde el anuncio del estado de alarma, el 13 de marzo, hasta el 9 de mayo de 2020. Para ello, se han analizado las 71 ruedas de prensa del Gobierno, en las que han participado 414 medios de comunicación, que han formulado 1.069 preguntas; además de las 1.080 publicaciones en las cuentas oficiales de La Moncloa en Facebook y Twitter, y las informaciones sobre España publicadas en los dos principales diarios de seis países (Italia, Francia, Alemania, Bélgica, Reino Unido y Estados Unidos). Los resultados muestran una presencia permanente del Gobierno para ofrecer información, compareciendo hasta tres veces por día en rueda de prensa, de acuerdo con una estrategia destinada a controlar los temas y los encuadres y con lenguaje bélico asociado a la unidad nacional. En redes sociales los contenidos relacionados con la información administrativa o de servicio (Galán-Galán, 2000, Almansa-Martínez, 2008) prevalecen sobre la comunicación imagen (Salerno, 2000), con un claro peso de las ruedas de prensa y una divergencia entre los intereses comunicativos de la ciudadanía y del Gobierno, que renuncia a una interacción real con ella. En cuanto a las informaciones de la prensa extranjera, se han identificado 778 noticias sobre la Covid-19 en España, con prevalencia en la prensa estadounidense y, fundamentalmente, sobre temas económicos en lugar de sanitarios.

\section{Palabras clave}

Covid-19; Coronavirus; Pandemias; Comunicación institucional; Comunicación política; Comunicación de crisis; Gobierno de España; Ruedas de prensa; Prensa escrita; Diarios; Medios sociales; Facebook; Twitter; Infodemias; Relaciones públicas; Marca España. 


\begin{abstract}
The Covid-19 pandemic has disrupted societies, having health, economic, political, and communication implications. Governments have had to plan and implement immediate communication strategies to explain the actions that have been taken and to manage public health campaigns. This research analyzes the Spanish Government's communication strategy at national and international level since the announcement of the state of alert on 13 March until 9 May 2020. To this end, the 71 press conferences held by the Government have been analyzed, with the participation of 414 media outlets that have asked 1,069 questions, in addition to 1,080 publications on the official accounts of La Moncloa on Facebook and Twitter and information about Spain in the two main newspapers in six countries (Belgium, France, Germany, Italy, USA, and UK). The results show a permanent presence of the Government, offering information via up to three press conferences on some days, revealing a strategy to control the subjects of discussion and their framing with warlike language associated with national unity. On social networks, the content related to administrative or service information prevails over image communication, with a clear dominance of press conferences and divergence between the communication interests of citizens versus the Government, preventing a true interaction between them. Regarding foreign press reports, 778 news items on Covid-19 in Spain were identified, with a prevalence in the US press and on economic rather than health issues.
\end{abstract}

\title{
Keywords
}

Covid-19; Coronavirus; Pandemics; Institutional communication; Political communication; Crisis communication; Government of Spain; Press conferences; Newspapers; Social media; Facebook; Twitter; Infodemics; Public Relations; Spain country brand.

\section{Introducción}

Desde la declaración de emergencia nacional ante la crisis sanitaria, a mediados de marzo de 2020, la información se ha convertido en un bien preciado y valioso para hacer frente a la situación (Casero-Ripollés, 2020). En toda gestión de crisis, la comunicación es un elemento esencial en la estrategia de fijar los autores participantes, la realidad de la situación, las consecuencias que se derivan y las implicaciones personales y colectivas. Si la crisis se inserta en una situación de pandemia sanitaria, la concurrencia de factores se multiplica y es necesario acometer acciones de comunicación para mantener la fluidez de una información veraz y para cerrar directrices de comportamiento social a través de la sensibilización y la educación ciudadana (Almansa-Martínez; Fernández-Torres, 2011; Nazaro; Crozzoli; Álvarez-Nobell, 2019).

En el caso de España, se han centrado en las comparecencias públicas, en su mayoría en formato de ruedas de prensa, en las que el presidente y los ministros han tenido una presencia constante, con el objetivo de suministrar información permanente, configurando así una estrategia de agenda-setting y de encuadre. Desde esta perspectiva, la actuación gubernamental deviene en proactiva con la información de las decisiones, que son comunicadas en las ruedas de prensa del presidente y de sus ministros, configurando por tanto las temáticas a partir de las decisiones del ejecutivo. Por otro lado, los encuadres sobre cómo estructurar cognitivamente la pandemia han sido una lucha constante entre los actores políticos de la Covid-19, como son:

- El ejecutivo: sobre el ritmo de la situación y las propuestas en el enfoque de la salida a la pandemia con un control de los ritmos y de la secuencia de sus actos. Además, la especial configuración organizativa de España, con la sanidad transferida a las Comunidades Autónomas y los diferentes ritmos, implica cuadros de tensiones interterritoriales sobre las soluciones y las propuestas.

- Partidos políticos: con el objetivo de participar en el proceso, pero con la problemática de que la terminología utilizada por el Gobierno, de conflicto bélico con un enemigo exterior y común, dificulta las críticas de los partidos políticos. En este sentido, la dicotomía entre apoyo frente a crítica ha sido uno de los principales asuntos de discusión política.

- Medios de comunicación: con sus propias líneas editoriales en una situación política española muy divergéticamente activa. Los medios han realizado sus propios encuadres ante la situación mediante la inclusión/exclusión, las jerarquizaciones informativas y nuevas propuestas de actuación.

- Actores sociales en actividades de lobby: que quieren coparticipar en los procesos de decisiones políticas sobre la resolución de los problemas económicos, principalmente. Así, las medidas gubernamentales crean tensiones entre salud y economía, que ha sido uno de los referentes en el proceso de ayudas a la salida de la crisis.

Todo este entramado de actores se ve supeditado a la fuerza informativa que obtiene el Gobierno en una pandemia, por lo que la mayoría de ellos llevan a cabo acciones reactivas a las decisiones gubernamentales. En este sentido, la Organización Mundial de la Salud acuñó el término infodemia (OMS, 2020) para describir la excesiva información sobre una situación en la que aparecen numerosos bulos y desinformaciones, señalando además en un informe sobre la comunicación y la Covid-19, que los gobiernos deben desplegar estrategias de comunicación sanitaria para informar de manera rápida, clara y transparente:

“La comunicación del riesgo en el país y la participación de la comunidad (risk communication and community engagement, RCCE) es una intervención crítica de salud pública en todos los países. Éstos deben estar prepara- 
dos para comunicar la situación de manera rápida, regular y transparente a la población. Todos los países deben tener redes de comunicación de salud pública y personal de participación comunitaria, y estar preparados para dar las respuestas adecuadas ante posibles casos. Los gobiernos deben coordinar las comunicaciones con las organizaciones que actúan ante la crisis sin olvidar la comunidad. La OMS está dispuesta a coordinarse y apoyar a los países en sus respuestas de comunicación y participación comunitaria" (OMS, 2020).

El primer contagio por Covid fue identificado en China en noviembre de 2019; en febrero de 2020 llegó a Europa y en marzo fue declarado pandemia por la OMS. Desde entonces, se ha estudiado el impacto social que está teniendo la enfermedad desde múltiples puntos de vista. Desde el mundo académico se han publicado varios trabajos, especialmente del campo de las ciencias de la salud, pero también de la comunicación (Xifra, 2020; Casero-Ripollés, 2020; Fontrodona; Muller, 2020; Mejía et al., 2020; Mancero; Larrea-Naranjo; Ruales-Parreño, 2020; Ubillos-Landa et al., 2020; Huynh, 2020; Cinelli et al., 2020; etc.).

\section{Comunicación y Gobierno de España}

El Gobierno de España ha sido activo desde el principio de la pandemia, ofreciendo información actualizada a través de las webs de los Ministerios de Sanidad, Consumo, Interior, Presidencia..., pero también realizando ruedas de prensa, comunicados, concediendo entrevistas a responsables en medios nacionales e internacionales o realizando declaraciones de forma diaria. Así debe ser, puesto que los gobiernos tienen que estar implicados con la información pública, relaciones públicas y asuntos públicos (Wilcox et al., 2001; Gil-Ramírez; Gómez-de-Travesedo-Rojas; Almansa-Martínez, 2019).

La comunicación gubernamental es fundamental en una democracia y en un momento de crisis todavía más. La búsqueda de la transparencia y de una gestión pública positiva llevan al gobierno a utilizar todo tipo de soportes y herramientas para hacer llegar la información a sus ciudadanos. Para ello, los equipos de comunicación responsables de la gestión informativa diseñan estrategias que plasman a través de (Mas-Manchón; Guerrero-Solé, 2019):

- tácticas orales: discursos del presidente, ministros y demás responsables gubernamentales; conferencias de prensa, tal y como se ha adelantado en el epígrafe anterior; entrevistas en los medios de comunicación, etc.;

- tácticas escritas: por ejemplo, las más publicitarias, como las campañas de lavado de manos o explicación de horarios durante el confinamiento, a través de anuncios en los medios tradicionales o en redes sociales, folletos, etc.;

- tácticas visuales: fundamentalmente ejecutadas a través de redes sociales y televisión.

La estrategia del discurso institucional seguida por el Gobierno persigue establecer un canal directo con la ciudadanía, interesada en recibir información sobre la situación y conocer los diversos escenarios de la actualidad. Esa presencia permite establecer los marcos de la discusión, por lo que es esencial dar información veraz con datos contrastados:

- Generar espacios comunicativos constantes para la sociedad y los medios de comunicación. Se ha operacionalizado con las ruedas de prensa diarias que se han organizado desde el Gobierno. En esos espacios se suministra información que posteriormente es irradiada por los medios en sus espacios comunicativos.

- Empatía con los actores directamente implicados en la pandemia, ya sean las personas contagiadas u otros colectivos públicos, como sanitarios, personal de seguridad y miembros de las Fuerzas y Cuerpos de Seguridad del Estado, de transporte o de servicio. Las muestras son numerosas, desde los aplausos para el personal sanitario a las 20 horas cada día, hasta las referencias de apoyo y de cercanía en todos los discursos institucionales. Es lo que Sartori $(1998$, p. 115) define como videopolítica, política dirigida a construir espacios emocionales.

- Participación de especialistas y expertos en el proceso de decisión ante la situación; dar voz a los expertos. En este sentido, las continuas apelaciones a expertos como base de las decisiones gubernamentales se han observado en todos los discursos políticos realizados en las ruedas de prensa. Asimismo, la comisión técnica que ha informado cada día de la evolución de la pandemia en España estaba formada por personal sanitario, de Defensa, Policía Nacional, Guardia Civil y Transportes.

- Recurrir a canales comunicativos adecuados a los objetivos institucionales, que permitan transmitir el mensaje de la manera más adecuada a las características de los públicos. A ello responde, por ejemplo, la organización el 18 de abril del acto La infancia pregunta, protagonizado por el ministro de Ciencia e Innovación, Pedro Duque y el director del Centro de Coordinación de Alertas y Emergencias Sanitarias, Fernando Simón, sometidos a preguntas de niños y jóvenes.

- Tomar decisiones adecuadas a las necesidades sociales y saber comunicarlas.

- Informar de las acciones que se están llevando a cabo para combatir la pandemia.

\section{Metodología y objetivos de la investigación}

El objetivo general del presente artículo es investigar las estrategias comunicativas del Gobierno de España durante la gestión de la crisis del coronavirus Covid-19. Entre los objetivos específicos cabe señalar los siguientes:

O1. Analizar las ruedas de prensa para conocer la frecuencia, participantes y temáticas.

O2. Conocer qué medios han participado en las ruedas de prensa, volumen de preguntas formuladas y temáticas. O3. Comparar la actividad comunicativa del Ejecutivo con los intereses de la ciudadanía en redes sociales, analizando la interacción entre ambos. 
O4. Comprobar el tratamiento y peso de las ruedas de prensa, base de la estrategia comunicativa del Ejecutivo, en sus canales en redes sociales.

05. Conocer la presencia de España en la prensa internacional en relación con la Covid-19.

O6. Averiguar los temas sobre los que más publica la prensa extranjera sobre España y el coronavirus.

Para ello se ha seguido una metodología mixta, analizando las actividades comunicativas llevadas a cabo por el Gobierno en comparecencias públicas y en los perfiles gubernamentales en redes sociales y estudiando su presencia en los diarios de referencia de seis países.

Así, se han analizado 71 ruedas de prensa del Gobierno siguiendo la técnica del análisis de contenido, tras realizar un visionado de todas las comparecencias celebradas durante el periodo comprendido entre el anuncio del estado de alarma (13 de marzo) hasta el 9 de mayo. En esos actos han participado 414 medios de comunicación, que han formulado 1.069 preguntas.

Se analizan dos redes sociales, Facebook y Twitter, por ser las de principal actividad del Gobierno de España y las que concentran un mayor número de seguidores, además de ser también las de mayor uso por parte de la ciudadanía en España (IAB Spain, 2019), excepción hecha de WhatsApp, que supera ligeramente a Facebook como red más usada en nuestro país ( $88 \%$ vs. $87 \%$ ), pero no es empleada por Moncloa como canal de comunicación ordinario y regular, sólo con fines puntuales. YouTube e Instagram, con un $68 \%$ y $54 \%$, respectivamente, gozan de mayor penetración que Twitter (50\%), pero es, en cambio, esta última red la más usada para informarse y debatir sobre temas de actualidad política y social en España (Borge-Bravo; Esteve-del-Valle, 2020).

El artículo analiza la actividad comunicativa desplegada en Facebook y Twitter durante las 50 jornadas de la fase más dura de confinamiento de la población, es decir, el período comprendido entre el viernes 13 de marzo y el 1 de mayo, última jornada previa al inicio de la denominada fase 0 de la desescalada, que se inicia el 2 de mayo con las primeras medidas de alivio general del confinamiento.

De entre todas las cuentas que en ambas redes tiene el Gobierno de España, pertenecientes a ministerios, organismos y servicios oficiales, se estudian en concreto las 1.080 publicaciones realizadas en @desdelaMoncloa (Twitter) y @PalaciodelaMoncloa (Facebook), ya que son las genéricas del Gobierno, las que más seguidores suman y las que se corresponden con la autoridad competente o mando único establecido en el artículo 4 del Real decreto por el que se declara el estado de alarma (RD 463/2020), la Presidencia del Gobierno. Dentro de cada una de

Tabla 1. Publicaciones y número de seguidores en las principales redes sociales de Moncloa.

\begin{tabular}{|l|c|r|}
\hline Red social & Publicaciones & Seguidores \\
\hline Twitter & 854 & 718.000 \\
\hline Facebook & 226 & 229.000 \\
\hline Instagram & 176 & 42.500 \\
\hline YouTube & 31 & 6.500 \\
\hline
\end{tabular}

ellas se analiza el número de publicaciones por día y su contenido (información, ruedas de prensa, publicidad, agenda o ajeno), el formato (sólo texto, imagen, vídeo o enlace) y el nivel de interacción de los contenidos publicados, computando número de likes que acumulan, las veces que han sido compartidos o retwiteados y los comentarios que han generado, además de las respuestas de Moncloa a esos comentarios.

Asimismo, se ha recurrido al análisis de contenido de los dos principales periódicos de seis países: Italia, Francia, Alemania, Bélgica, Reino Unido y Estados Unidos durante un marco temporal de estudio muy acotado: las dos semanas que van del 24 de abril al 8 de mayo, ambas fechas incluidas.

Las cabeceras seleccionadas han sido Le monde, Le figaro, The times, The daily telegraph, Frankfurter allgemeine zeitung, Süddeutsche zeitung, Corriere della sera, La repubblica, The Washington post, The New York times, Het laatste nieuws y Het nieuwsblad / De gentenaar, debido a que, como indica Casero-Ripollés (2020), el público, ante un contexto informativo complejo y de riesgo, opta por fuentes informativas establecidas y con una trayectoria larga.

Con esta búsqueda se localizaron 778 noticias que se analizaron mediante una metodología cuantitativa basada también en el análisis de contenido (Krippendorff, 1990; Wimmer; Dominick, 2006). Con este fin, se establecieron unas variables para elaborar el corpus empírico.

\section{Resultados}

Los resultados muestran una gran actividad mediática, con ruedas de prensa permanentes por parte del presidente del Gobierno y de sus ministros. En ellas participaron 414 medios de comunicación nacionales e internacionales que formularon 1.060 preguntas.

\subsection{Ruedas de prensa}

\subsubsection{Comparecencias del presidente del Gobierno}

El presidente del Gobierno ha celebrado un total de 13 ruedas de prensa en los dos meses de pandemia analizados, en las que ha ido informando de las actuaciones del Gobierno y de las medidas adoptadas a lo largo de los días que han pasado desde el anuncio de la declaración del estado de alarma el día 13 de marzo. 
Tabla 2. Ruedas de prensa del presidente del Gobierno.

\begin{tabular}{|c|c|c|c|c|c|}
\hline $\begin{array}{c}\text { Fecha } \\
\text { comparecencia }\end{array}$ & $\begin{array}{l}\text { Duración } \\
\text { discurso }\end{array}$ & Duración preguntas & Tiempo total & $\begin{array}{l}\mathrm{N}^{\circ} \text { de medios } \\
\text { participantes }\end{array}$ & Número preguntas \\
\hline 12 marzo & $26: 56$ & $13: 02$ & $39: 58$ & 9 & 9 \\
\hline 13 marzo & $8: 35$ & - & $8: 35$ & - & - \\
\hline 14 marzo & $24: 07$ & $28: 59$ & $53: 06$ & 10 & 18 \\
\hline 17 marzo & $28: 27$ & $27: 31$ & $55: 58$ & 8 & 11 \\
\hline 21 marzo & $37: 43$ & $23: 18$ & 1:01:01 & 8 & 17 \\
\hline 22 marzo & $19: 52$ & $29: 18$ & $49: 10$ & 7 & 16 \\
\hline 28 marzo & $16: 56$ & $30: 49$ & $47: 45$ & 10 & 16 \\
\hline 4 abril & $25: 20$ & $34: 51$ & $49: 00$ & 9 & 18 \\
\hline 12 abril & $17: 20$ & $22: 39$ & 39:59 & 9 & 9 \\
\hline 18 abril & $22: 42$ & $45: 32$ & 1:08:14 & 9 & 17 \\
\hline 25 abril & $20: 17$ & $44: 28$ & $1: 04: 45$ & 9 & 19 \\
\hline 2 mayo & $20: 55$ & $57: 10$ & 1:18:05 & 10 & 27 \\
\hline 9 mayo & $19: 57$ & $36: 18$ & $56: 25$ & 9 & 26 \\
\hline \multicolumn{4}{|l|}{13 ruedas de prensa } & 107 & 203 \\
\hline
\end{tabular}

Los medios (prensa, radio, televisión, agencias de noticias) nacionales e internacionales que han participado han sido 107. La mayoría han sido medios nacionales (94 en total), entre los que predomina la prensa escrita. Entre los 13 medios internacionales predominan las agencias de noticias (Reuters, Bloomberg, France Press), seguidas de los periódicos como Financial times, The New York times o la BBC. Uno de los aspectos que se han cuidado mucho en las ruedas de prensa es que hubiera presencia de medios extranjeros, principalmente europeos, puesto que una parte muy significativa del turismo proviene de países europeos (Fernández-Souto; Vázquez-Gestal; Corbacho-Valencia, 2016) y coadyuva a la construcción de la marca-España.

Con relación a las preguntas formuladas por los medios, cabe destacar que han sido un total de 203 cuestiones. Los primeros días esas preguntas se remitían a un chat habilitado por la Secretaría de Estado de Comunicación e iban siendo trasladadas por su responsable con la referencia al medio que las formulaba. Posteriormente, a raíz de las protestas de los medios, se modificó el método y se permitieron algunas preguntas formuladas directamente por los periodistas a través de videollamada, algo que en ocasiones ocasionaba problemas de conexión, pero que se iban solventado con la repetición o la formulación de la pregunta sin imagen.

Del análisis textual del presidente del Gobierno se puede extraer una serie de temas que han caracterizado sus comparecencias, como son:

1. Lenguaje bélico. En la mayoría de sus intervenciones Pedro Sánchez ha recurrido a términos bélicos como batalla, enemigo, combatir o guerra. Esta terminología se ha centrado, sobre todo, en las primeras comparecencias, en las que la pandemia se estaba expandiendo por España. Los ejemplos son varios:

"Esta es una batalla que vamos a ganar, sobre eso no hay discusión; la vamos a ganar. Lo importante es que el precio que paguemos por esa victoria sea el mínimo" (14 marzo).

"El enemigo no está a las puertas. Penetró hace ya tiempo en la ciudad. Ahora la muralla para contenerlo está en todo aquello que hemos puesto en pie como país, como comunidad [...] Y con esas armas, pararemos al virus, resistiremos y lo venceremos. Y lo haremos unidos" (17 marzo).

"Angustia, esperanza y desolación. Fuerza del enemigo que nos ha invadido, enemigo tan letal, lucha firme guerra. Todavía estamos lejos de esa victoria. No podemos deponer las armas, sino que tenemos que seguir combatiendo. Nada nos va a detener hasta vencer esta guerra" (12 abril).

"Hoy, los españoles, como el resto de la humanidad, hacemos frente común a un enemigo formidable, un enemigo mortal que ha invadido nuestras ciudades, nuestros pueblos, poniendo en peligro nuestras vidas, nuestra salud, nuestra economía. En definitiva, nuestra manera de vivir. Los campos de batalla allí donde se vive con crudeza toda la crueldad de nuestro enemigo están en los hospitales" (12 abril).

2. La búsqueda de la unidad nacional. Desde el primer momento, se ha intentado evitar la confrontación, al menos de una manera explícita. Así, los llamamientos a la unión, al pacto o las apelaciones a acuerdos históricos en España, como los llamados Pactos de La Moncloa, han sido recurrentes. Algunas de las expresiones más utilizadas son:

"Por eso, insisto, coordinarnos y escucharnos no es una opción, es una obligación" (14 de marzo).

"Corresponsabilidad, unidad [...] Navegamos en la misma barca, remamos juntos [...] Compatriotas. Es nuestra obligación ponernos de acuerdo" (21 abril). 
3. El hecho de que la pandemia es un fenómeno internacional. Desde el primer momento se ha recurrido a la salvaguarda de que la epidemia es un fenómeno internacional que se ha extendido a todos los países y la situación española no es excepcional.

"Todos los países del mundo se están viendo sometidos a esta durísima prueba. Es una situación que la propia OMS reconoce que carece de precedentes" (17 marzo).

"Más de un tercio de los seres humanos, y quiero subrayar esta cifra, más de un tercio de los seres humanos, estamos en estos momentos confinados en nuestras casas para luchar contra el virus, contra el enemigo común" (28 marzo).

4. La excepcionalidad de la situación, que ocupará un lugar en la historia de Europa y del mundo. Las apelaciones a la historicidad de la epidemia intentan explicar un fenómeno que se estudiará en la historia internacional:

“Nuestro país también está soportando la emergencia sanitaria más grave del último siglo. Una catástrofe para la que la humanidad no estaba preparada, pese a los avisos de las epidemias sufridas en las últimas décadas como el ébola y el SARS" (21 marzo).

"Porque, no os quepa ninguna duda, estamos ante la gran crisis de nuestras vidas" (4 abril).

"Estos días, líderes de países de nuestro entorno han dicho y los hemos escuchado que esta situación es la más grave que han vivido nuestras sociedades desde la II Guerra Mundial y probablemente no les falta razón. En nuestro país, ciertamente, solo los muy mayores, que conocieron las penalidades de la Guerra Civil y de la postguerra, guardan en su memoria situaciones colectivas más duras que las presentes. Salvo ellos, el resto de las generaciones que hoy vivimos en España nunca, jamás a lo largo de nuestras vidas, habíamos tenido que afrontar colectivamente algo tan duro, tan difícil" (21 marzo).

“Nos encontramos en una situación que nadie con menos de 90 años ha conocido" (18 abril).

5. La dureza de las medidas. En los discursos realizados por el presidente de Gobierno se han enfatizado las duras decisiones tomadas:

"Las medidas que vamos a adoptar son drásticas y van a tener desgraciadamente consecuencias" (14 de marzo).

"Tal y como anuncié en mi última comparecencia, esta semana nos aguardaban las horas más oscuras, las horas más duras, las horas más amargas [...] Y cada vez que me comuniqué con vosotros solicité lo mismo: solicité sacrificio, resistencia y moral de victoria para derrotar al virus" (4 abril).

6. Los responsables políticos se centrarán en las recomendaciones de los expertos. En toda situación de crisis de tipo sanitario, y en otros tipos de crisis, la participación de los expertos es un elemento de todo manual de crisis. Por ello, las apelaciones a las decisiones de especialistas son muy frecuentes:

“Contamos, eso sí, con el saber de los expertos internacionales, con el saber y el conocimiento de los expertos nacionales y autonómicos, a quienes quiero reconocer su importante labor, que nos orienta y guía nuestra determinación, nuestra audacia y nuestra resistencia" (17 marzo).

"La ciencia no dispone aún de todo el conocimiento, pero el único conocimiento lo tiene la ciencia y ella debe guiarnos y tenemos que, también, tomar las decisiones desde los responsables públicos" (4 abril).

Esta estrategia es acorde con la percepción sobre el papel de los expertos en situaciones de crisis que recoge en el informe del Reuters Institute for the Study of Journalism (Nielsen et al., 2020), que señala, tal y como se refleja en el gráfico 1 , que son el colectivo al que mayor fiabilidad le confiere la ciudadanía.

Consecuencia de ello, los expertos son los públicos que mayor fiabilidad confieren a los ciudadanos, algo en lo que el Gobierno ha basado muchas de sus acuerdos con argumentarios sobre que las decisiones adoptadas son a partir de las recomendaciones efectuadas por los científicos y expertos. Las diarias ruedas de prensa, dirigidas por el Director del Cen-

\begin{tabular}{|c|c|c|c|c|c|c|c|c|c|c|}
\hline \multicolumn{11}{|l|}{ Spain } \\
\hline & $0 \%$ & $10 \%$ & $20 \%$ & $30 \%$ & $50 \%$ & $60 \%$ & $70 \%$ & $80 \%$ & $90 \%$ & $100 \%$ \\
\hline Scientists, doctors, health experts & $84 \%$ & & & & & & & & \multicolumn{2}{|l|}{$10 \%$} \\
\hline National health organisations & $69 \%$ & & & & & & $17 \%$ & & & $12 \%$ \\
\hline Global health organisations & $77 \%$ & & & & & & & $12 \%$ & & $9 \%$ \\
\hline News organisations & $51 \%$ & & & & $24 \%$ & & & & & $23 \%$ \\
\hline Government & $46 \%$ & & & & $16 \%$ & & & & & $35 \%$ \\
\hline PeopleI know & $33 \%$ & & & $33 \%$ & & & & & & $31 \%$ \\
\hline Politicians & $31 \%$ & & & $22 \%$ & & & & & & $45 \%$ \\
\hline PeopleIdon't know & $16 \%$ & & $29 \%$ & & & & & & & $52 \%$ \\
\hline
\end{tabular}


tro de Coordinación de Alertas y Emergencias Sanitarias, integradas en su totalidad por expertos en sanidad, movilidad, defensa y seguridad, son un ejemplo de la importancia que desde el Gobierno se ha otorgado al papel de los expertos.

Las comparecencias han participado de diversas funciones que caracterizan a los discursos políticos como son:

- Función conativa. Con permanentes recomendaciones sobre el comportamiento social, personal o económico. Uno de los aspectos que más han estado presentes en las declaraciones ha sido las normas de salud, puesto que son esenciales para evitar la propagación del virus. Para ello se ha recurrido a elementos visuales, sonoros (audio y audiovisuales) y orales.

- Función referencial. En las intervenciones del presidente del Gobierno se ha apelado a multitud de referencias cuantitativas sobre, por ejemplo, número de análisis realizados, número de afectados, número de personas curadas o gasto sanitario.

- Funciones poética y expresiva. Recurso a metáforas, con una preponderancia evidente de las de carácter bélico, que han sido utilizadas en gran parte de los discursos. Valga como ejemplo la rueda de prensa ya comentada del 12 de abril sobre "un enemigo mortal que ha invadido nuestras ciudades" y los "campos de batalla" que son los hospitales.

Las ruedas de prensa han seguido siempre una misma presentación visual en lo que se refiere al presidente del Gobierno. Comparecencia de pie, tras un atril, en la sala de prensa del Palacio de La Moncloa, con los asientos de público y prensa vacíos. En todas ellas se realizan preguntas y el presidente toma nota de las mismas, así como del periodista que formula cada una, para a continuación, como estrategia de cercanía y empatía, iniciar la respuesta con el nombre de ese periodista.

Otra de las características organizativas de las ruedas de prensa, también seguida de forma invariable, es la estrategia de no dar toda la información durante

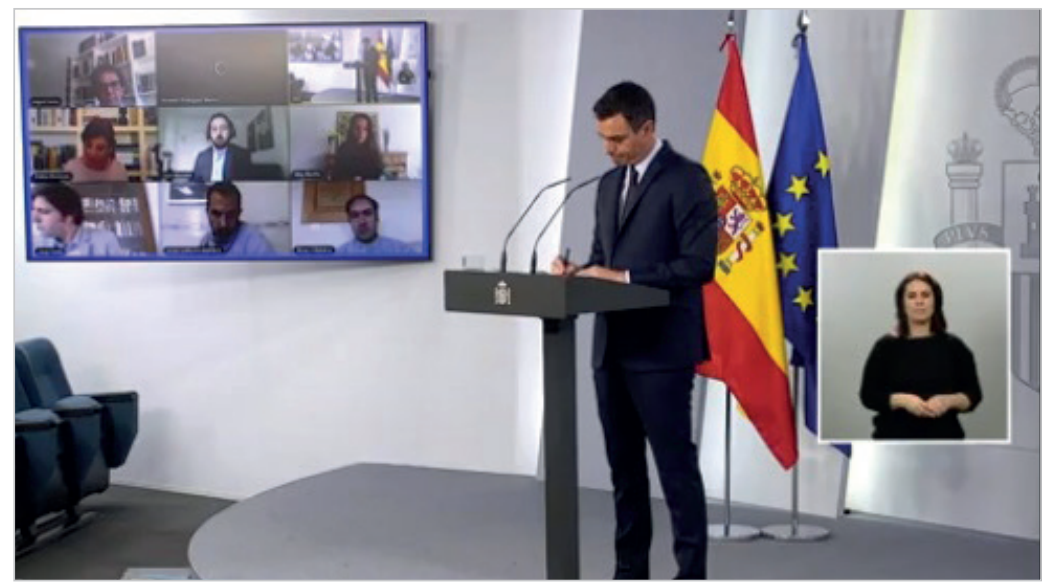

Figura 1. Disposición formal de las ruedas de prensa del presidente del Gobierno. https://www.lamoncloa.gob.es/multimedia/videos/presidente/Paginas/2020/02052020_ presiintervencio.aspx

la intervención inicial y reservar datos, los más esperados a veces, para proporcionarlos en las respuestas ofrecidas a las preguntas de los periodistas. Uno de los casos más claros puede verse en la comparecencia del 2 de mayo, en la que el presidente informa de la creación de un "fondo especial para la reconstrucción" de 16.000 millones de euros puestos a disposición de las Comunidades Autónomas; es en las respuestas a los periodistas y no antes donde se desglosan los criterios de ese reparto.

La organización y gestión de las preguntas formuladas por los periodistas a los diferentes miembros del Gobierno, como ya se ha apuntado, han sido objeto de polémica desde el inicio del estado de alarma. Como resultado se han sucedido dos formatos:

1. Los periodistas formulan sus preguntas previamente en un grupo de WhatsApp habilitado para ello y el Secretario de Estado de Comunicación traslada, posteriormente, las preguntas a los comparecientes ya sean el presidente del Gobierno, los ministros o los miembros del Comité de Gestión Técnica del Coronavirus. Ejerciendo un papel de selección a partir de sus criterios profesionales, citaba el medio y la pregunta formulada, pero también ejercía un papel unificador de preguntas sobre idéntica temática con expresiones como

"Entre las preguntas que se formulan hay alguna, no demasiadas [...]";

"Son numerosas las preguntas que tenemos a raíz, sobre todo, de la intervención que acaba de realizar, en la que ha hablado de un permiso retribuido";

“Presidente, a lo largo de su intervención muchos medios están preguntando por responsabilidades, su responsabilidad, la responsabilidad del Gobierno";

"Todos los medios le preguntan ahora mismo y le piden que concrete".

2. A raíz de las críticas de los periodistas, se modificó el formato de las ruedas de prensa, pasando a uno en el que unos medios seleccionados a priori formulan las preguntas de manera directa a los intervinientes a través de videoconferencia. Para ello, se llegó a un acuerdo con las asociaciones de la prensa sobre el criterio a seguir para seleccionar a esos medios, que consiste en distinguir dos bloques de medios, los acreditados en Moncloa de manera permanente y los que se han acreditado para informar específicamente sobre esta situación.

Las críticas de los periodistas se concretaron en un manifiesto $(A B C, 2020)$ firmado por más de 500 profesionales bajo el título La libertad de preguntar" (RTVE, 2020), en el que se señala que: 
“En una situación de crisis el derecho a la información es más importante que nunca. Con España en estado de alarma, el Gobierno disfruta de unos poderes muy superiores a los normales, por lo que es importante que la prensa realice su labor de control, más aún cuando el Parlamento ha limitado enormemente su actividad. La principal forma de ejercer esta función desde el periodismo es a través de las preguntas -y las repreguntas-a los miembros del Gobierno".

Sobre la percepción que los españoles tienen de la situación de la Covid-19, el informe Navigating the 'Infodemic' del Reuters Institute (2020) realiza una primera valoración del papel de los gobiernos como suministradores de información a la ciudadanía. Las preguntas persiguen conocer si la función informadora de los gobiernos ha sido adecuada o no.

\begin{tabular}{|c|c|c|c|}
\hline & $\begin{array}{l}\text { The government has } \\
\text { helped me understand } \\
\text { the pandemic }\end{array}$ & $\begin{array}{l}\text { The government has } \\
\text { explained what I can do } \\
\text { in response to the } \\
\text { pandemic }\end{array}$ & $\begin{array}{l}\text { The government has } \\
\text { exaggerated the pandemic }\end{array}$ \\
\hline UK & $63 \%$ & $77 \%$ & $11 \%$ \\
\hline US & $45 \%$ & $56 \%$ & $21 \%$ \\
\hline Germany & $50 \%$ & $68 \%$ & $19 \%$ \\
\hline Spain & $40 \%$ & $53 \%$ & $13 \%$ \\
\hline South Korea & $60 \%$ & $59 \%$ & $22 \%$ \\
\hline Argentina & $64 \%$ & $75 \%$ & $22 \%$ \\
\hline
\end{tabular}

Gráfico 2. Actitud hacia las comunicaciones gubernamentales en torno a la pandemia del coronavirus (Reuters Institute, 2020).

Tal y como se muestra en el gráfico 2, España es el país en el que la información facilitada por el Gobierno ha contribuido en menor medida a que la ciudadanía, según su percepción, comprenda esta pandemia, con un porcentaje de tan solo un $40 \%$, frente a resultados del $77 \%$ en Gran Bretaña o del $68 \%$ en Alemania.

Por lo que respecta a la vertiente informadora (administrativa o de servicio) de los gobiernos, sobre cómo comportarse ante el virus, España ocupa una posición intermedia, con un 53\% de aprobación, frente al $45 \%$ de los Estados Unidos o el $50 \%$ de Alemania.

Por último, cuando se ha preguntado a los encuestados sobre el grado de exageración de sus gobiernos sobre la pandemia, España ocupa el segundo lugar en cuanto a visión más realista del problema, con tan sólo un porcentaje del 13\% de desaprobación, tras Gran Bretaña (11\%), pero mejorando las posiciones de los demás países analizados.

\subsubsection{Comparecencias de los ministros}

El Gobierno también ha organizado ruedas de prensa en las que han participado todos los ministros del gabinete, como mínimo una por ministro, para informar cómo afecta la pandemia y qué medidas se están adoptando en su ministerio.

Así, las 58 ruedas de prensa realizadas desde la declaración del estado de alarma han contado con 116 intervenciones de ministros, ya que en muchas de ellas han participado varios miembros del Ejecutivo. Las más numerosas han sido ruedas de prensa que han contado con cuatro ministros, que se corresponden con aquellos que el artículo 4 del real decreto por el que se declara el estado de alarma (España, 2020) nombra "autoridades competentes delegadas", los Ministerios de Sanidad, de Defensa, Interior y de Transportes, Movilidad y Agenda Urbana.

Tabla 3. Ministerios con mayor número de comparecencias.

\begin{tabular}{|l|l|l|}
\hline \multicolumn{1}{|c|}{ Ministerio } & Comparecencias & \% Participación \\
\hline Salvador Illa, ministro de Sanidad & 33 ruedas de prensa \\
\hline María Jesús Montero, ministra de Hacienda y Portavoz del Gobierno & 16 ruedas de prensa \\
\hline Fernando Grande-Marlaska, ministro del Interior & 14 ruedas de prensa & 13,79 \\
\hline José Luis Ábalos, ministro de Transportes, Movilidad y Agenda Urbana & 12 ruedas de prensa & 12,06 \\
\hline
\end{tabular}

En estos cuatro ministerios ha recaído la política informativa regular del gobierno, ya que entre ellos acumulan dos terceras partes de todas las comparecencias de miembros del Ejecutivo, cifra que se incrementa notablemente si tenemos en cuenta que, además, la rueda de prensa diaria del Comité de Gestión Técnica está protagonizada por altos funcionarios de los ministerios que son autoridades competentes delegadas, entre los que se encuentran tres de los anteriores ( $\mathrm{Sa}$ nidad, Interior y Transportes). En todas esas comparecencias han participado medios nacionales, autonómicos, locales y extranjeros, con un total de 307 participaciones. 
La prensa escrita es el tipo de medio que mayor participación ha tenido en las ruedas de prensa del Gobierno, seguida de las radios y de las televisiones. Esa presencia de medios ha reflejado la distribución territorial española, ya que la concurrencia de medios autonómicos ha sido relevante. También han participado diversos medios locales, que han sido agrupados bajo el epígrafe de otros medios.

De estos medios:

- Telecinco (Informativos) es el que ha participado en más ruedas de prensa,

- Diario.es ocupa el primer lugar de los de prensa escrita;

- Servimedia es la agencia con mayor presencia;

- Cope lidera al sector radiofónico;

- Diario médico a los medios especializados;

- la agencia Reuters es el medio extranjero que mayor participación ha tenido en las ruedas de prensa.

Tal y como se puede observar, el criterio de selección de medios no ha sido el grado de penetración de cada uno en su sector específico, puesto varios de los que mayor participación han tenido no lideran el ranking de audiencias del mismo.

Por lo que respecta a la estructura temporal de las ruedas de prensa, las intervenciones iniciales de los comparecientes suman en torno a 21 horas y 15 minutos, mientras que el tiempo total dedicado a las respuestas ha sido superior, 33 horas y 50 minutos. En este sentido, los medios de comunicación han formulado un total de 866 preguntas en las 58 ruedas de prensa ministeriales, lo que ofrece una media de 14,9 preguntas por comparecencia. Sobre el tiempo de respuesta, resalta la respuesta realizada a un periodista del diario El país (Carlos Cué) que tuvo una duración de más de 10 minutos.

\subsection{Comunicación del Gobierno en redes sociales}

\subsubsection{Actividad general}

Twitter es la red que concentró la gran actividad comunicativa online del Gobierno durante el período analizado, 854 publicaciones en los 50 días comprendidos entre el 13 de marzo y el 1 de mayo, frente a las 226 de Facebook, que se distribuyen cronológicamente del modo que se observa en el gráfico 3.
Tabla 4. Participación según el tipo de medio de comunicación.

\begin{tabular}{|l|c|}
\hline \multicolumn{1}{|c|}{ Tipo medio } & No de participaciones \\
\hline Televisiones nacionales & 23 \\
\hline Televisiones autonómicas & 21 \\
\hline Diarios & 102 \\
\hline Agencias & 26 \\
\hline Especializados en sanidad & 15 \\
\hline Especializados en economía & 16 \\
\hline Radios nacionales & 36 \\
\hline Radios autonómicas & 13 \\
\hline Extranjeros & 21 \\
\hline Otros & 34 \\
\hline Total & 307 \\
\hline
\end{tabular}

Tabla 5. Medios con mayor número de participaciones.

\begin{tabular}{|c|c|}
\hline Tipo medio & Medio \\
\hline \multirow{3}{*}{ Televisiones nacionales } & Telecinco \\
\hline & La sexta \\
\hline & TVE \\
\hline \multirow{3}{*}{ Diarios } & Diario.es \\
\hline & El periódico de Cataluña \\
\hline & La vanguardia/20 minutos \\
\hline \multirow{3}{*}{ Agencias } & Servimedia \\
\hline & $E F E$ \\
\hline & Europa press \\
\hline \multirow{3}{*}{ Medios especializados } & Diario médico \\
\hline & Eleconomista \\
\hline & Expansión \\
\hline \multirow{3}{*}{ Radios } & Cope \\
\hline & Onda cero \\
\hline & SER \\
\hline \multirow{3}{*}{ Medios extranjeros } & Reuters \\
\hline & Clarín \\
\hline & Associated press/Le figaro \\
\hline
\end{tabular}

Pese a partir de un uso similar el día 13 de marzo, la evolución de la crisis de coronavirus acentúa el uso de Twitter, que pasa de los 7 tweets publicados ese día a picos de 30, 34 o 46 el 31 de marzo, en el que se alcanza la mayor actividad en esta red coincidiendo con la celebración del Consejo de Ministros que aprobó una amplia batería de medidas para luchar contra las consecuencias sociales de la crisis, tales como el real decreto ley de medidas urgentes para proteger y asistir a víctimas de violencias machistas, la suspensión de desahucios, ayudas al alquiler, moratoria de hipotecas, prohibición del corte de suministro de luz, agua y gas, subsidios extraordinarios para trabajadores en paro, etc.; lo que fue bautizado por parte del Gobierno como "ampliar el escudo social".

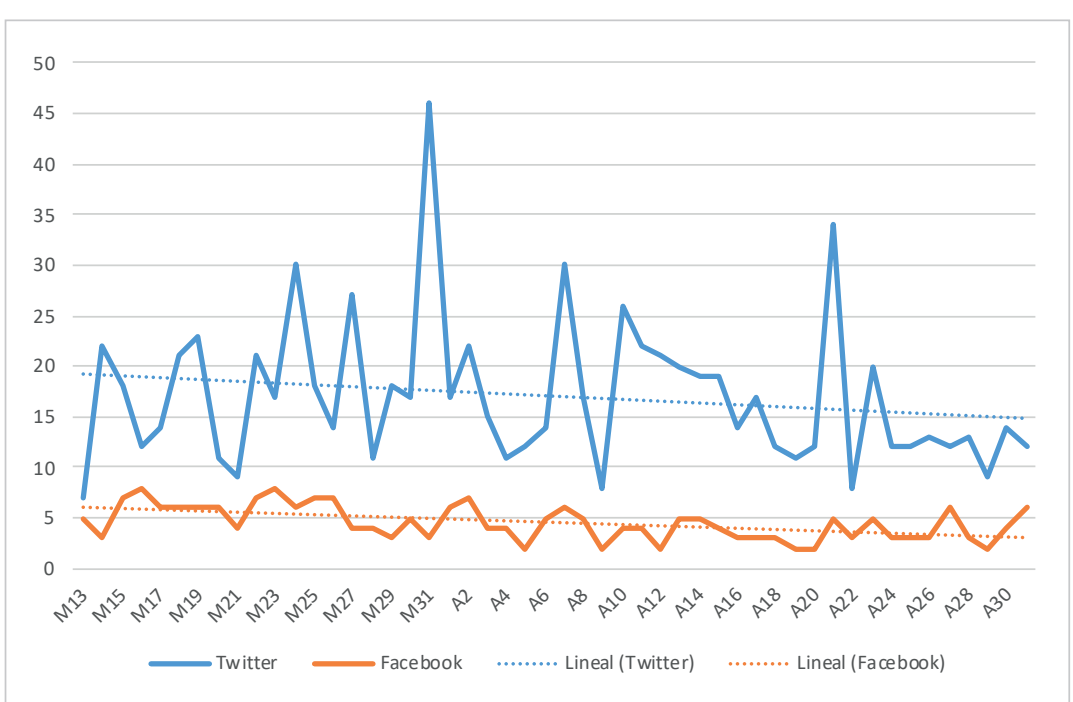

Gráfico 3. Evolución temporal de las publicaciones en Facebook y Twitter del Gobierno de España durante la crisis de la Covid-19. 
El segundo pico de actividad en esta red (34 publicaciones) se produjo el 21 abril, coincidiendo también con la celebración de un Consejo de Ministros, en el que se acuerda prolongar el estado de alarma del día 26 de abril al 10 de mayo, además de una nueva ampliación del llamado escudo social, incrementando la protección por desempleo y los expedientes de regulación temporal de empleo (ERTE), reduciendo cotizaciones y aprobando diversas medidas fiscales destinadas a pequeñas y medianas empresas, y autónomos; además de anunciar dos de las medidas de mayor trascendencia pública de este período:

- limitar el precio máximo de venta de las mascarillas quirúrgicas;

- permitir desde el 26 de abril la salida de los menores de 14 años de su domicilio para dar paseos durante un máximo de una hora.

Los otros dos días con registros destacados de actividad, 24 de marzo y 7 de abril, son nuevamente jornadas de celebración de Consejo de Ministros y, por tanto, de aprobación y publicación de diversas medidas. En ambos se acuerda solicitar sendas prórrogas del estado de alarma al Congreso de los Diputados, junto con la aprobación, en el primero, de créditos a empresas o medidas para garantizar la alimentación de menores vulnerables y, en el segundo, del real decreto ley de medidas urgentes en materia de empleo agrario o el estudio de seroprevalencia para conocer el grado de expansión de la Covid-19 en España.

Ninguna de las 4 jornadas señaladas anteriormente para Twitter coincide sin embargo con los días de mayor actividad en Facebook, que son el 16 y 26 de marzo, con 8 publicaciones cada uno. El primero de ellos, una de las jornadas además con menor actividad en Twitter, se corresponde con la rueda de prensa del ministro del Interior, Fernando Grande-Marlaska, para dar cuenta del restablecimiento de los controles en las fronteras terrestres de España con la Unión Europea. El segundo día coincide con la aprobación en el Congreso de los Diputados de la primera prórroga de 15 días del estado de alarma y la participación de Pedro Sánchez en el Consejo Europeo que estudia las medidas comunitarias de lucha contra el coronavirus, además de en la cumbre virtual del G20, centrada en la cooperación internacional con el mismo fin.

La actividad media del Gobierno en Twitter es de 17,1 publicaciones por día, con una gran oscilación entre jornadas, que va desde los 7 tweets el 13 de marzo a los 46 el día 31. En Facebook la media de publicaciones es casi 4 veces inferior a la de Twitter, 4,5 publicaciones por día, aunque con menor oscilación, pues la diferencia entre las jornadas con menor y mayor actividad es de sólo 6 entradas, 2 en los días que menos se publica y 8 en los que más. En ambas redes la tendencia de actividad es levemente decreciente, concentrando de media mayor número de publicaciones en los 25 primeros días de estado de alarma que en los 25 segundos, aunque sin diferencias abultadas.

\subsubsection{Interacción de la ciudadanía}

Vistos los días de mayor actividad por parte del Gobierno en redes y los eventos que generaron tal actividad comunicativa, aquellos, por tanto, de los que más profusamente se pretendió informar, procede comprobar si existe relación o no con las publicaciones que mayor interés despertaron entre los usuarios, expresado este en términos de likes, contenidos compartidos y comentarios. En relación con Twitter, las tres entradas con mayor número de interacciones son las que se muestran en la figura 2 .

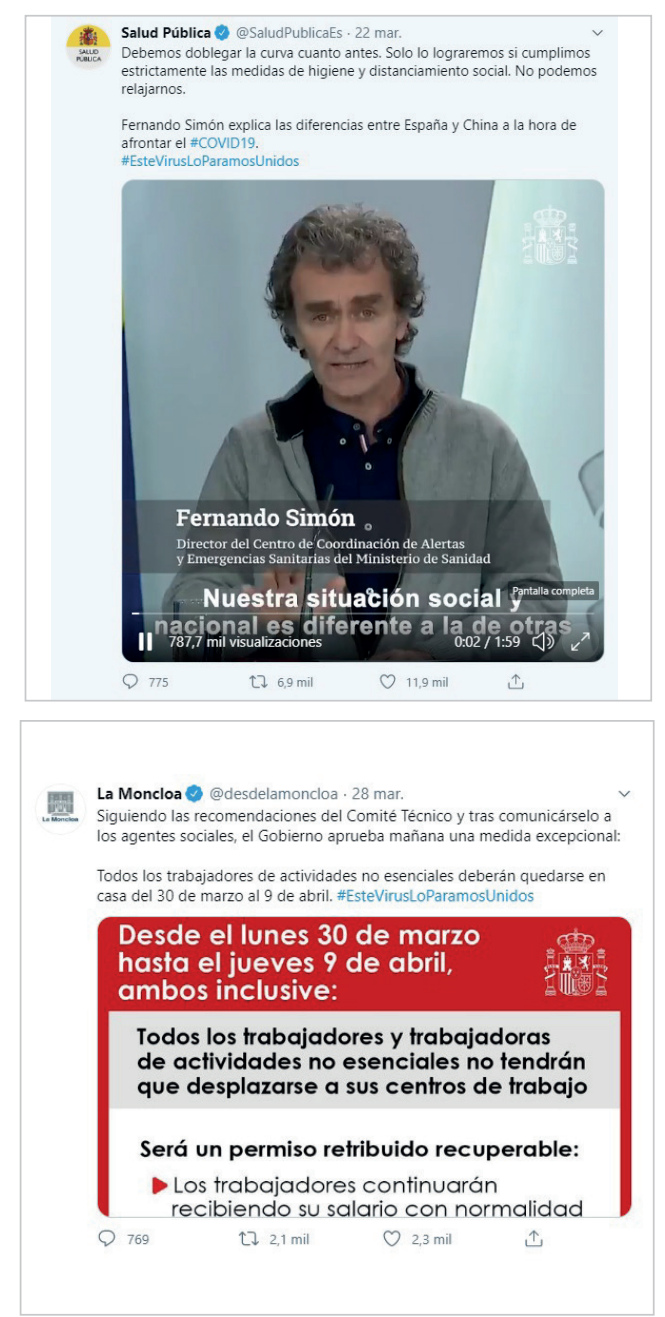

Figura 2. Tweets con mayor número de likes y retweets. https://twitter.com/desdelaMoncloa

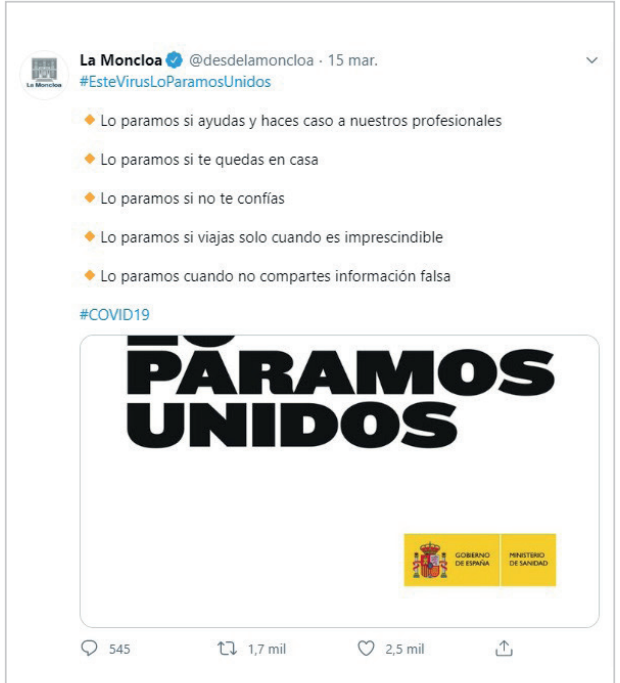

La Moncloa @ @desdelamoncloa . 14 mar.

El Consejo de Ministros extraordinario de hoy ha aprobado el Real Decreto Ley por el que se declara el Estado de Alarma para la gestión de la situación \#EsteVirusLoParamosUnidos

Aquí, las principales medidas previstas

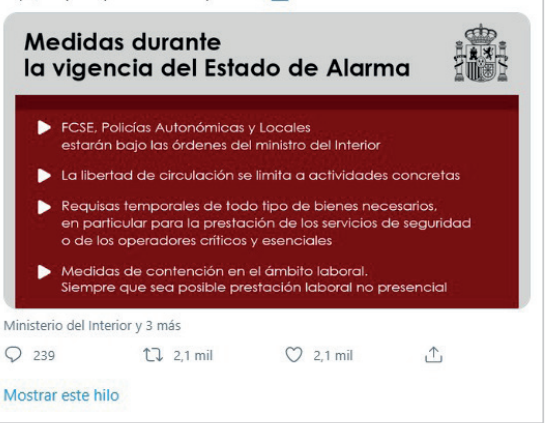


Ninguno de los tweets con mayor número de likes y número de veces compartido se corresponde con los días de mayor actividad en Twitter por parte del Gobierno. Los cuatro que rebasan la barrera de los 2.000 likes o las 1.500 veces compartidos son contenidos publicados en marzo, durante los primeros 15 días del estado de alarma, concretamente el 14 y 15, los dos primeros días de vigencia del confinamiento, junto con el 22 y 28 de marzo. El contenido que más 'me gusta' (11.900 likes) y más veces ha sido compartido (6.900 retweets) por los usuarios es un clip de vídeo de unos 2 minutos de duración, retweeteado por Moncloa desde la cuenta @SaludPublicaES (cuenta oficial del Gobierno de España sobre cuestiones relativas a la salud pública) el 22 de marzo, en el que el director del Centro de Coordinación de Alertas y Emergencias Sanitarias del Ministerio de Sanidad Fernando Simón explica las diferencias entre España y China a la hora de abordar la crisis de la Covid-19. Se trata de un extracto de la rueda de prensa diaria del Comité de Gestión Técnica que encabeza el propio Simón.

Las otras tres publicaciones con mayor éxito se sitúan a mucha distancia de ésta.

Destaca en segundo lugar en cuanto a likes (2.500) y en cuarto en número de veces compartido (1.700) un tweet de contenido netamente publicitario, de los pocos que hay en el período analizado, publicado el 15 de marzo con el cartel de la campaña Este virus lo paramos unidos y las llamadas básicas a la acción de no viajar, respetar el criterio profesional, permanecer en casa o no compartir fake news.

El segundo contenido más veces compartido (2.100) y tercero en número de likes (2.300) es un tweet que Moncloa publicó el 28 de marzo tras la aprobación de la paralización de toda la actividad laboral no esencial entre el 30 de marzo y el 9 de abril, es decir, los días de confinamiento más estricto, explicando en qué consistía el denominado "permiso retribuido recuperable".

Por último, cabe destacar con 2.100 likes y 1.700 comparticiones el tweet publicado el mismo día de entrada en vigor del estado de alarma, acompañado de una imagen que detalla las medidas generales en las que se concreta dicha situación.

Junto con los likes y el número de veces que cada contenido ha sido compartido, se ha analizado también el número de comentarios que ha suscitado cada publicación, sin que se observe una correlación inmediata entre este hecho y el anterior. Es cierto que entre las 25 publicaciones más comentadas en Twitter, de las 854 totales, se encuentran tres de las anteriores, la rueda de prensa de Simón (puesto 14), la información sobre el permiso retribuido recuperable (15) y la campaña Este virus lo paramos unidos (23); también están las cuatro que se muestran en la figura 3 como más comentadas entre las 26 con más likes, pero los puestos de más relevancia en una y otra categoría son para publicaciones diferentes.

Tal y como se puede observar en la figura 3, son los vídeos íntegros de cuatro ruedas de prensa del presidente del Gobierno, emitidas en directo a través de Twitter, las cuatro publicaciones que más comentarios provocan por parte de los usuarios de esta red, concretamente las de los días 14, 21 y 28 de marzo y 4 de abril, que se corresponden con la posterior al Consejo de Ministros del sábado 14 , en el que se declara el estado de alarma y las de los tres sábados siguientes, en las que el presidente, manteniendo una pauta comunicativa regular, comparece para hacer balance de la semana transcurrida y anuncia nuevas medidas para la entrante. De entre ellas, la más comentada (3.000 entradas) es la del día 21, en la que Sánchez analiza la primera semana de estado de alarma y anuncia a la población que la ola de mayor número de positivos y los días más duros están aún por llegar.

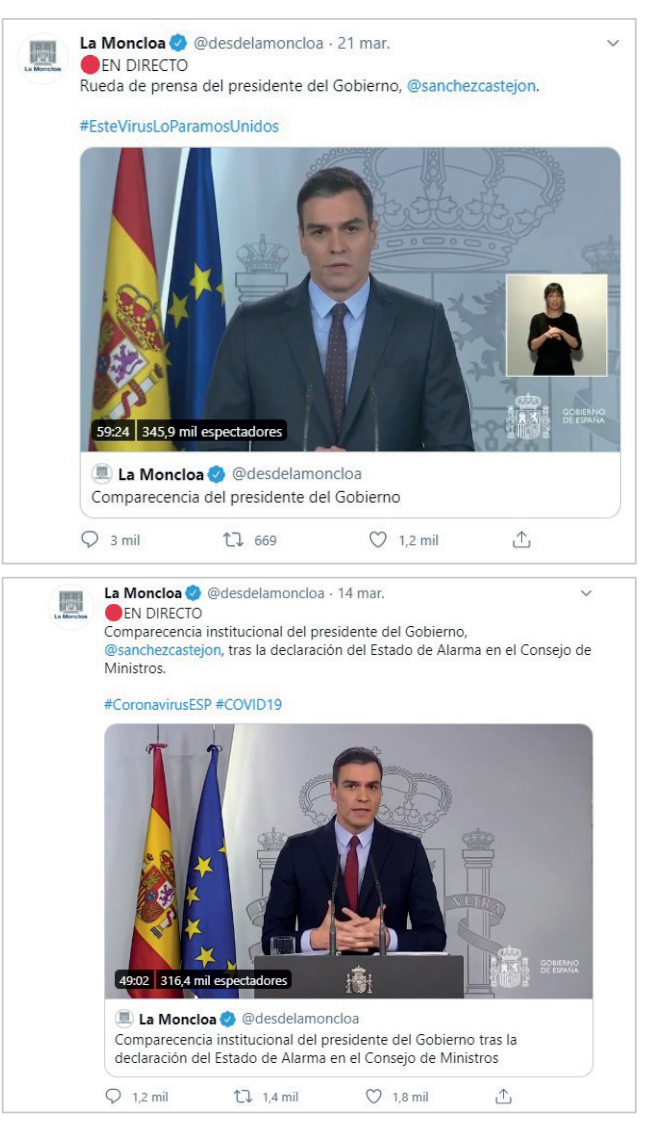

Figura 3. Tweets con mayor número de comentarios. https://twitter.com/desdelaMoncloa

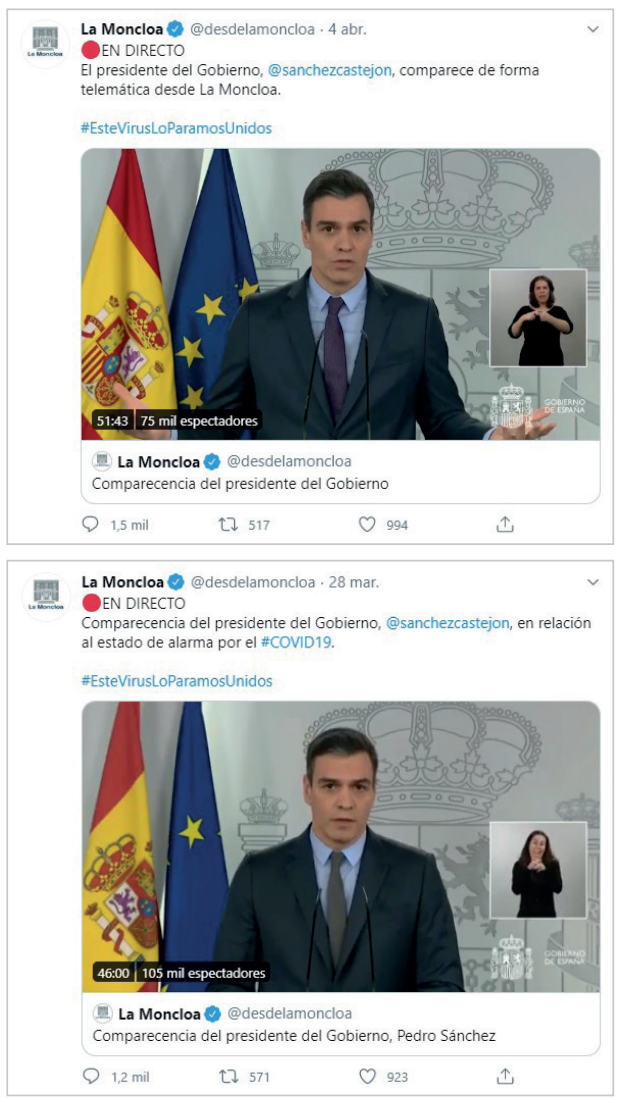

Q 1,2 mil $\quad$ ¿ $571 \quad \bigcirc 923$ 
En segundo lugar (1.500 comentarios) se encuentra la comparecencia del sábado 4 de abril, en la que el presidente anuncia una nueva prórroga del estado de alarma hasta el 25 de ese mismo mes y habla, por primera vez, del alivio del confinamiento tras esa fecha y la sucesión a lo largo del tiempo de diferentes estados de alarma.

En tercer y cuarto lugar se ubican respectivamente las ruedas de prensa del 14 y 28 de marzo, con 1.200 comentarios cada una de ellas. La del 14 es la ya comentada de la aprobación por parte del Consejo de Ministros del estado de alarma, mientras que la del 28 se corresponde con el anuncio del confinamiento más estricto y la aprobación del permiso retribuido recuperable para los trabajadores que ven suspendida su actividad laboral durante esos días. Nuevamente se trata de publicaciones correspondientes al mes de marzo y el primer sábado de abril, es decir, a las primeras semanas de la crisis.

La preferencia por las ruedas de prensa a la hora de comentar publicaciones en Twitter queda aún más de manifiesto si se amplía el foco más allá de estos cuatro tweets con mayor número de entradas, pues entre las 27 publicaciones más comentadas se encuentran 25 ruedas de prensa, 12 de Sánchez entre las 13 primeras. Tan sólo el tweet del 28 de marzo que incluye una imagen con las condiciones del permiso retribuido recuperable (771 comentarios) y otro del día 14 de contenido publicitario, con el cartel de la campaña Este virus lo paramos unidos (545 comentarios), analizados ambos ya en el apartado de publicaciones con más likes, consiguen igualar el impacto en comentarios de las ruedas de prensa.

La única comparecencia no protagonizada por el presidente que consigue ubicarse entre los 13 tweets más comentados es un evento original, no estrictamente una rueda de prensa, que protagonizan Fernando Simón y el ministro de Ciencia e Innovación, Pedro Duque, el 18 de abril bajo el título La infancia pregunta, ya analizada en el apartado dedicado a las ruedas de prensa. No se trata del vídeo íntegro del evento, sino de un fragmento de 2 minutos en el que el ministro explica el modo correcto de ponerse la mascarilla y que se convierte en el séptimo tweet más comentado. Además de esto, hasta el puesto 27 de publicaciones con más comentarios antes indicado, se encuentran ruedas de prensa o extractos de las mismas de la ministra de Hacienda y portavoz del Gobierno, María Jesús Montero, del ministro de Sanidad, Salvador Illa, del vicepresidente segundo y ministro de Derechos Sociales, Pablo Iglesias, de la vicepresidenta tercera y ministra de Asuntos Económicos, Nadia Calviño, de la vicepresidenta cuarta y ministra para el Reto Demográfico, Teresa Ribera y alguna otra de Fernando Simón.

En Facebook, al igual que ocurría en Twitter, ninguna de las publicaciones con más interacción de los usuarios se corresponde con los días de mayor actividad del Gobierno en esta red, los días 16 y 26 de marzo. En lo que sí coincide, e incluso agudiza al extremo la tendencia ya observada en Twitter, es en el peso de las entradas relacionadas con las ruedas de prensa a la hora de estimular la participación de los usuarios, pues todas las publicaciones con más 'me gusta', comentarios y comparticiones, considerando las cuatro principales de cada una de las categorías, a excepción de una, la tercera más compartida, son ruedas de prensa del presidente del Gobierno, especialmente las de los sábados; cierto es que, como se comentará más adelante, son las comparecencias de prensa el contenido más abundante en esta red.

La publicación que suma un mayor número de 'me gusta' (7.300) es el vídeo íntegro de la rueda de prensa en la que Pedro Sánchez anuncia la paralización de toda la actividad productiva no esencial del país y la aprobación del permiso laboral retribuido recuperable, ya analizada en Twitter como el tercer tweet con más likes y el segundo con más retweets.

Le siguen con 6.100 likes la rueda de Sánchez del 21 de marzo, en la que hace balance de la primera semana de aplicación del estado de alarma, la más comentada en Twitter, la comparecencia del día siguiente (4.900 likes) en la que anuncia la primera prórroga del estado de alarma y la del día 17 de marzo (4.817), martes de Consejo de Ministros, en el que se aprueba el real decreto ley de medidas urgentes extraordinarias para hacer frente al impacto económico y social del coronavirus; ninguna de esta dos generó una actividad destacada en Twitter.

Las diferencias de impacto entre una red y otra quedan de manifiesto al comprobar, por ejemplo, que las dos publicaciones con más likes en Twitter, el vídeo de Fernando Simón explicando las diferencias entre China y España en la lucha contra el coronavirus y la campaña publicitaria Este virus lo paramos unidos, en Facebook, frente a los miles de 'me gusta' señalados en las publicaciones anteriores, estas suman tan sólo 992 y 414 , respectivamente.

En relación con el número de veces que han sido compartidas las publicaciones de La Moncloa en Facebook, cabe destacar que la segunda y cuarta entradas con más éxito en este aspecto coinciden con el apartado anterior, pues se trata de las ruedas de prensa del presidente del Gobierno del 21 de marzo (balance de la primera semana), compartida 3.500 veces, junto con la del día 17 (medidas económicas), que fue compartida en su muro por 3.300 personas. Sí existen diferencias en el primer y tercer lugar.

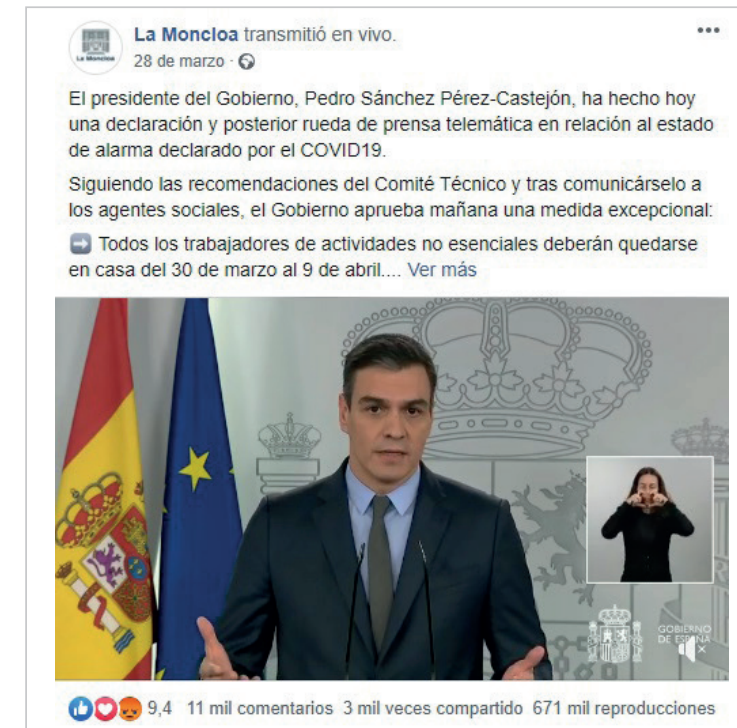

Figura 4. Publicación con más 'me gusta' en Facebook. https://www.facebook.com/PalaciodelaMoncloa 
La publicación más compartida en Facebook (4.800 veces) se corresponde con la rueda de prensa del presidente del sábado 14 de marzo, en la que da cuenta de la aprobación en Consejo de Ministros de la declaración del estado de alarma; ya vista al analizar Twitter, pues era el tercer contenido más retweeteado y el cuarto con mayor número de likes. En este apartado, además de las dos entradas ya señaladas, destaca en tercer lugar (3.400 veces compartida) una publicación del 26 de abril, la única destacable de Facebook que no es una rueda de prensa, sino una publicación informativa, acompañada de vídeo explicativo, sobre la autorización a salir de casa, desde ese mismo día, para los menores de 14 años durante una hora y hasta $1 \mathrm{~km}$. de distancia de su domicilio.

Por último, en relación con Facebook, cabe analizar las publicaciones con mayor número de comentarios, aspecto en el que sí se observa un mayor grado de coincidencia con Twitter, pues el contenido más comentado en ambas redes es el mismo, la rueda de prensa del presidente del Gobierno del 21 de marzo (15.000 comentarios), ya analizada, sobre el balance de la primera semana del estado de alarma. También el segundo contenido más comentado en Facebook (11.000 entradas) se corresponde con uno de los más comentados en Twitter aunque en cuarto lugar, la comparecencia, también de Sánchez, sobre el parón de la actividad económica y el permiso retribuido recuperable.

En tercer y cuarto lugar, con 10.000 y 9.100 comentarios, se encuentran dos ruedas de prensa presidenciales del mes de abril, las de los sábados 18 y 25 respectivamente, que se corresponden con el anuncio de extensión del estado de alarmar hasta el día 9 de mayo, junto con medidas de alivio del confinamiento para los menores de 14 años, y con la presentación inicial del plan de desescalada de dicho estado de alarma. Ninguna de las dos se encuentra entre las publicaciones destacadas en Twitter.

Aunque en Facebook hay alguna presencia mayor de publicaciones destacadas correspondientes al mes de abril, el peso de las realizadas durante el mes de marzo, es decir, durante los 15 primeros días del estado de alarma, al igual que en Twitter, es incuestionable, pues a este período corresponden 9 de las 12 analizadas como destacadas.

Al margen de las publicaciones concretas que destacan en cada red, sumando las interacciones totales en Twitter y Facebook puede verse el diferente impacto que cada una de ellas tiene tanto en términos absolutos como relativos.
La Moncloa transmitió en vivo.

14 de marzo -0

El Gobierno decreta el Estado de Alarma para hacer frente a la emergencia sanitaria ocasionada por el coronavirus, COVID-19

El Consejo de Ministros extraordinario celebrado hoy ha aprobado el Real Decreto Ley que recoge las medidas que afectarán a todo el territorio nacional durante 15 días.

El presidente del Ejecutivo ha explicado que a partir de hoy la Autoridad Competente en todo el territorio será el Gobierno de España. Pedro Sánchez ha asegurado que entre todos y todas ... Ver más

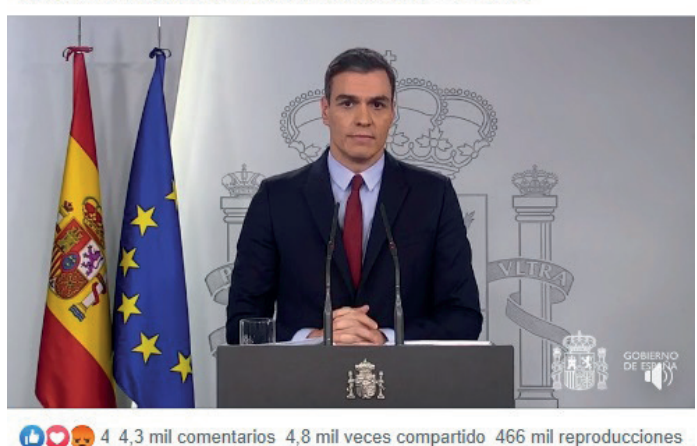

(1) 4 4,3 mil comentarios 4,8 mil veces compartido 466 mil reproducciones

Figura 5. Publicación más compartida en Facebook. http://facebook.com/PalaciodelaMoncloa

La Moncloa transmitió en vivo.

21 de marzo $\cdot \odot$

El presidente del Gobierno, Pedro Sánchez Pérez-Castejón, ha comparecido en rueda de prensa telemática para explicar las medidas que se están implementando ante el \#COVID19. Asimismo, Sánchez ha insistido en la necesidad de que toda la ciudadanía siga las indicaciones de las autoridades sanitarias en todo momento.

Pedro Sánchez ha manifestado que "si evitamos el contagio, liberamos camas para quien lo necesita, ganamos tiempo. Lo seres humanos somos el tiempo que respiramos.... Ver más

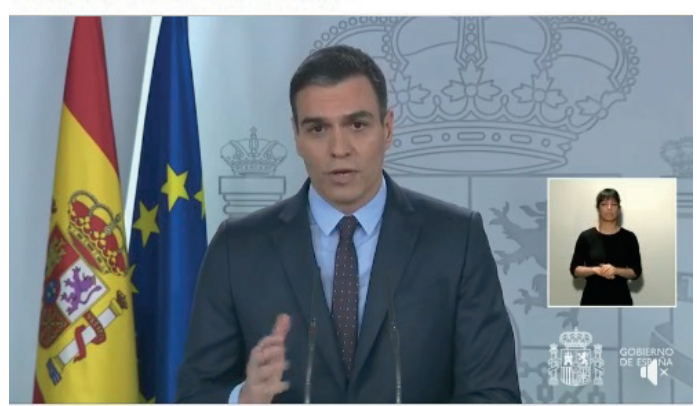

(1) 915 mil comentarios 3,5 mil veces compartido 652 mil reproducciones

Figura 6. Publicación con más comentarios en Facebook. http://facebook.com/PalaciodelaMoncloa

Tabla 6. Número de likes, contenidos compartidos y comentarios en Facebook y Twitter en el período analizado.

\begin{tabular}{|l|c|c|c|c|c|c|}
\hline \multirow{2}{*}{ Red social } & \multicolumn{2}{|c|}{ Likes } & \multicolumn{2}{c|}{ Compartidos } & \multicolumn{2}{c|}{ Comentarios } \\
\cline { 2 - 6 } & N & Media & N & Media & 171 & 80.925 \\
\hline Twitter & 214.254 & 251 & 146.325 & 124.983 & 553 & 372.662 \\
\hline Facebook & 243.980 & 1.080 & 1.649 & 95 \\
\hline
\end{tabular}

Con más del triple de seguidores en Twitter que en Facebook, la interacción entre usuarios y contenidos es mucho más baja en la primera que en la segunda, que con 500 mil usuarios menos y casi cuatro veces menos publicaciones, registra unas cifras absolutas de participación mayores a las de Twitter en todos los apartados, excepto en las publicaciones compartidas, en las que en todo caso Facebook sigue estando por delante en términos relativos, es decir, en media de contenidos compartidos por publicación, superior en más de tres veces a la media de Twitter.

Finalmente, en relación con la interacción real entre emisor y usuarios, la generación de conversación que cabría esperar de la actividad en redes sociales, hay que destacar que es inexistente, pues salvo cuestiones muy puntuales, prácticamente anecdóticas, no existe conversación real entre el Gobierno y sus seguidores en redes, que prácticamente nunca reciben respuesta a sus cometarios, preguntas u opiniones. 


\subsubsection{Contenidos de las publicaciones en redes sociales}

Tal y como se ha indicado en el apartado de metodología, uno de los objetivos fundamentales del trabajo consiste en el análisis de los contenidos de las publicaciones del Gobierno de España en redes sociales, de acuerdo con las categorías señaladas. Un aspecto en el que Twitter y Facebook difieren claramente.

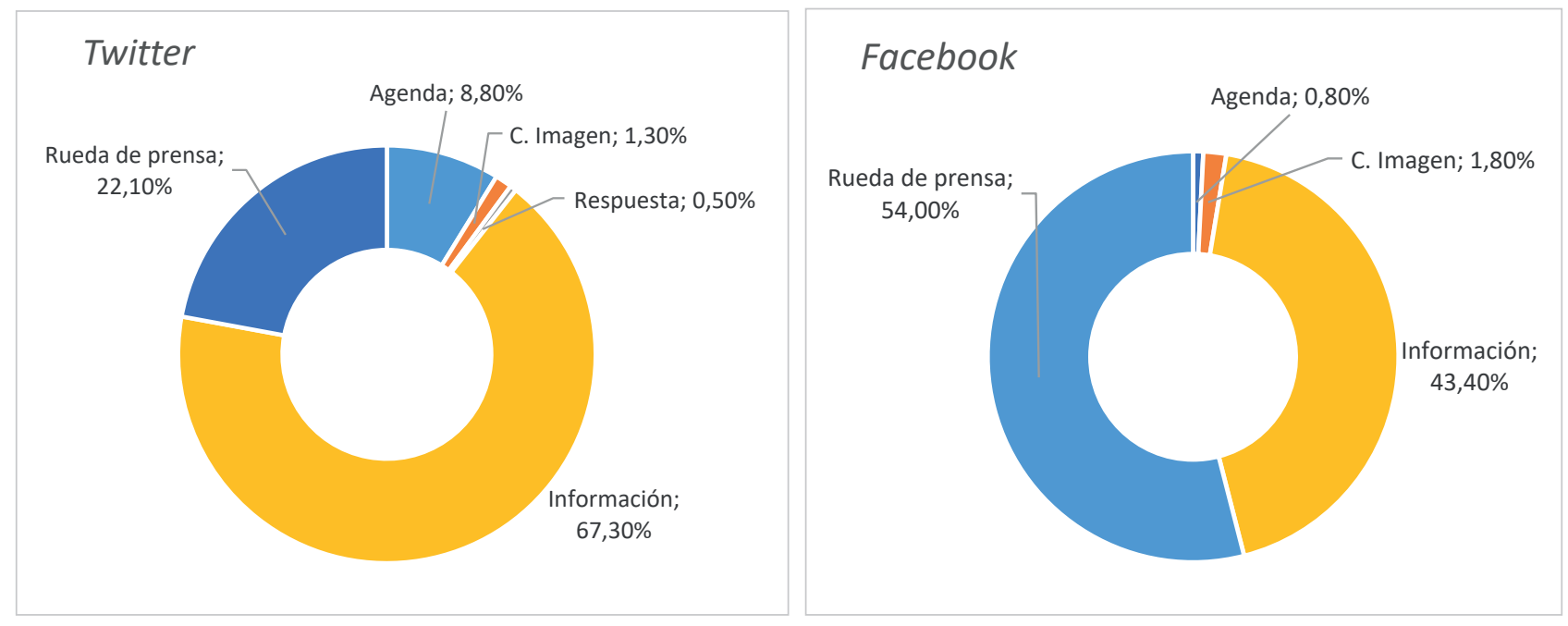

Grafico 4. Distribución de contenidos en Twitter y Facebook.

Tal y como se puede observar en el gráfico 4, la información y la reproducción íntegra de las ruedas de prensa son los contenidos claramente mayoritarios en ambas redes, significando casi el $90 \%$ de los contenidos de Twitter (89,4\%) y el $98 \%(97,4 \%)$ de los de Facebook, aunque la primera se inclina claramente por la información o comunicación administrativa y de servicio $(67,3 \%)$, frente a las ruedas de prensa, que significan un $22,1 \%$ de las publicaciones totales. Las comparecencias antes los medios son, en cambio, el contenido mayoritario en Facebook (54\%), con un peso de la información relativamente cercano $(43,4 \%)$.

La importancia de las ruedas de prensa se agudiza aún más si se tiene en cuenta que en dicha categoría tan sólo se han sumado las reproducciones íntegras o transmisiones en directo de las mismas, pero, especialmente en Twitter, hay otras publicaciones, clasificadas como información, que realmente estarían a medio camino entre ambas; son los resúmenes de dichas ruedas, elaborados en forma de clips de vídeo, generalmente de unos 2 minutos de duración, en los que se destacan los anuncios más importantes hechos por los comparecientes. En Twitter estos extractos suman 158 publicaciones, un 18,5\% del total de tweets publicados en el período analizado; añadidos a las ruedas de prensa, incrementarían el peso de estas hasta casi el $41 \%$, es decir, duplicarían su importancia en esta red y estarían casi a la par de la información, que, aun así, seguiría siendo el contenido principal $(48,8 \%)$.

En Facebook las píldoras informativas salidas de las ruedas de prensa son mucho más escasas que en Twitter, tan sólo se computan 22 publicaciones de este tipo, que sumadas a las ruedas de prensa, elevarían el peso de estas 10 puntos hasta el $64 \%$, dejando a los contenidos informativos, segundos en cualquier caso, en el 33\%. Es en Facebook por tanto donde las comparecencias de los miembros del Gobierno adquieren un mayor protagonismo, que prácticamente duplicarían a los contenidos informativos.

En relación con el resto de las categorías, sólo cabría destacar el peso de las publicaciones de agenda en Twitter (8,8\%), que se explica, frente a la escasa presencia en Facebook $(0,8 \%)$, fundamentalmente por el hecho de que el timeline de cada día arranca, prácticamente en todas las jornadas estudiadas, con un tweet que resume las previsiones informativas del Gobierno para el día en cuestión, hecho que no sucede en Facebook, donde las únicas entradas de este tipo se corresponden con dos vídeos que anuncian la previsión de reuniones, sin incluir más datos o información que la celebración misma del evento.

La comunicación imagen, en sentido estricto, pese a contar con contenidos destacados, como el tweet publicitario que consigue convertirse en la segunda publicación con más likes y la cuarta más veces compartida, apenas tiene importancia en el cómputo global, significa tan sólo en torno a un 1,5\% de las publicaciones de ambas redes.

En relación con la otra categoría investigada, los contenidos ajenos, cabe indicar que ni en Twitter ni en Facebook se han reproducido contenidos de fuentes ajenas al Gobierno. Afirmación matizable únicamente por dos hechos:

- además de las publicaciones de diversos ministerios u organismos del Gobierno de España, que se computan como propias, sí se reproducen publicaciones de entidades como Renfe, que, dado su carácter de empresa pública, tampoco se consideran ajenas;

- existen también algunos retweets, enlaces y publicaciones compartidas del Congreso de los Diputados, que aun siendo una institución independiente del Gobierno, no se han computado como ajenas porque su único contenido son 
vídeos con la señal institucional de las comparecencias del presidente del Gobierno ante la cámara o resultados de las votaciones en la misma de las iniciativas llevadas por el Gobierno; encontramos 7 publicaciones de este tipo tanto en Facebook como en Twitter.

El evidente peso informativo que la Covid-19 tiene en las jornadas analizadas queda de manifiesto también en el hecho de que el $100 \%$ de los contenidos publicados en Facebook durante este período por La Moncloa están relacionados con el coronavirus; mientras que en Twitter únicamente se encuentran 6 publicaciones sobre asuntos no relacionados con la emergencia sanitaria, un $0,7 \%$ del total.

Atendiendo a la distribución por días de los contenidos no se observan variaciones significativas a lo largo del período analizado, sino que tanto Twitter como Facebook siguen un patrón bastante regular de publicaciones. La primera suele iniciar cada jornada con la publicación de las previsiones informativas del día para a continuación, al margen de publicaciones puntuales de otro tipo, combinar la información de interés público con la transmisión en directo de la rueda de prensa diaria del Comité de Gestión Técnica del coronavirus, encabezado por Fernando Simón, y las comparecencias del presidente o ministros que den cuenta de la gestión de la crisis ese día. Tras estas ruedas de prensa suelen publicarse diversos tweets con clips de vídeo que resumen las declaraciones más destacadas realizadas por los protagonistas de estas y otras publicaciones con infografías o imágenes de todo tipo, que sintetizan los anuncios hechos o los acuerdos adoptados por el Gobierno ese día, dados a conocer también en las comparecencias públicas.

Facebook centra prácticamente toda su actividad en estos dos últimos asuntos. Emite también en directo cada día la rueda de prensa del Comité de Gestión Técnica y las de los ministros o cargos del Gobierno de turno, además de las del presidente; tras las cuales, a diferencia de Twitter, no suele, salvo en algunas ocasiones muy puntuales, publicar los clips de vídeo con las declaraciones más destacadas de los comparecientes. El resto de la jornada se completa con publicaciones de información administrativa o de servicio, tanto con infografías e imágenes que dan cuenta de los acuerdos y novedades diarias, ya comentadas, como de otro tipo.

Por último, es destacable el hecho de que, al margen de las diferencias en cuanto a contenidos en una y otra red y, más concretamente, al peso específico de las ruedas de prensa en ambas, tanto Facebook como Twitter emiten y archivan los vídeos íntegros de todas las ruedas de prensa celebradas en el palacio de La Moncloa. Tan sólo se detecta una comparecencia, de rango menor, que se retransmite en Facebook y no en Twitter el día 20 marzo, en la que comparecen el secretario de estado de Derechos Sociales y otros cargos medios del Ministerio que dirige el vicepresidente Pablo Iglesias para dar cuenta de los asuntos tratados en la reunión previa del Consejo Territorial de Servicios Sociales. Una comparecencia que ejemplifica, además, las premuras comunicativas del momento, pues en el vídeo disponible en la red pueden verse incluso los momentos previos al inicio de la retransmisión, con los paseos nerviosos por la tarima o las pruebas de sonido del secretario de estado antes de comenzar a hablar.

\subsubsection{Recursos audiovisuales e hipertexto}

En último lugar, ya al margen del contenido, cabe analizar las publicaciones desde el punto de vista formal, observando en qué medida éstas se basan simplemente en texto o si, a mayores, optan por enriquecerse con imágenes dinámicas y estáticas, vídeos o enlaces mediante los que ampliar la información incluida en el texto de dicha publicación. Se distinguen también las publicaciones, pocas, que simplemente se limitan a compartir contenidos de diferentes áreas de del Gobierno sin más aportación original por parte de la cuenta de Moncloa.

En ambas redes los recursos de este tipo (sin contar los enlaces externos, de los que se hablará más adelante) son mayoritarios, alcanzando el $100 \%$ de las publicaciones en el caso de Facebook y casi el $90 \%(88,9 \%)$ en Twitter, con un predominio claro del vídeo sobre la fotografía o imagen estática también en ambas redes, aunque en Twitter la importancia de uno y otro están más equilibradas (47,1\% vs. 38,6\%) que en Facebook, en donde domina claramente el vídeo, presente en el $67,3 \%$ de las publicaciones, sobre la imagen, incluida en un $30,1 \%$ de las entradas.

En relación con los otros dos recursos analizados, claramente minoritarios, el texto y los contenidos enlazados desde otras cuentas del Gobierno de España sin modificación de ningún tipo, puede observarse cómo tienen algo más de cabida en Twitter. En esta red un $11 \%$ de los tweets contienen únicamente texto, respetando el formato original de los primeros años de Twitter; son en prácticamente todos los casos publicaciones de contenido informativo que suelen desgranar de modo inmediato, casi síncrono, medidas o anuncios concretos hechos en ruedas de prensa. La presencia 

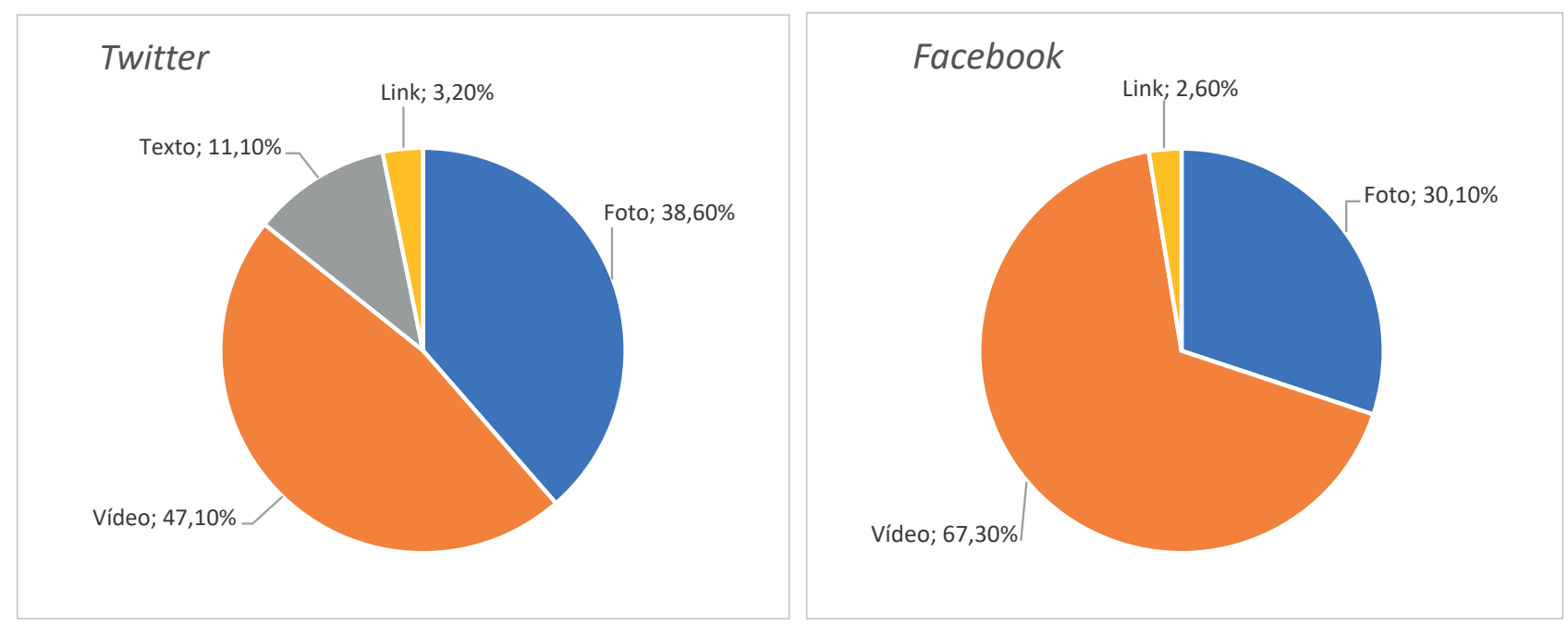

Gráfico 5. Recursos audiovisuales e hipertexto en Twitter y Facebook.

de contenidos compartidos directamente, sin comentario o añadido de ningún tipo, desde otras cuentas del Gobierno es prácticamente residual en ambas redes, responden a este formato un 3,20\% de los tweets y un $2,60 \%$ de las publicaciones en Facebook.

Si se analiza la importancia de estos recursos en función del contenido de la publicación, obviamente, la presencia del vídeo es casi unánime en las publicaciones relacionadas con las ruedas de prensa, tanto en la retransmisión íntegra de las mismas como en las píldoras informativas derivadas de ellas, pero su importancia puede verse también en las publicaciones clasificadas como informativas. Entre estas últimas la imagen estática o animada es mayoritaria, pues la incorporan un $47,7 \%$ de los tweets informativos y un $68,4 \%$ de las entradas en Facebook de este tipo, pero cuentan con vídeo un $33 \%$ y un $35,7 \%$, respectivamente, de los mismos. En resumen, un $98 \%$ de las publicaciones informativas de Facebook y un $81 \%$ de las de Twitter incorporan imagen o vídeo.

Junto con estos recursos multimedia, numerosas publicaciones incorporan también en el texto enlaces a webs a través de las que ampliar la información difundida en las redes sociales; se trata en la mayor parte de los casos de links al portal de Presidencia del Gobierno (laMoncloa.gob.es) o de ministerios y organismos públicos, en los que poder informarse con más detalle de anuncios hechos en rueda de prensa, acuerdos del Consejo de Ministros, del Comité de Gestión Técnica del coronavirus, etc. Recurren a ello el $36,4 \%$ de los tweets publicados y el $41,2 \%$ de las publicaciones en Facebook.

\subsection{España en la prensa internacional}

Tras el análisis de las dos principales cabeceras de prensa de los seis países analizados, el primer resultado que cabe destacar es que se ha identificado un total de 778 noticias que incluyen referencias a España y Covid; de ellas, se han estudiado 117 , clasificadas por sesgo positivo (60 noticias) o negativo (57).

El período objeto de estudio abarca del 24 de abril al 8 de mayo, ambos incluidos. Todos los días se han identificado noticias que contienen los parámetros de búsqueda mencionados, siendo el día 25 de abril y el 1 y 8 de mayo los de menor actividad, con una sola una noticia, mientras que el día 28 se registra el mayor número de publicaciones, con un total de 20; tal y como se muestra en el gráfico 6.

Puede indicarse que, además de estas diferencias por días, existe también una gran divergencia entre países a la hora de publicar noticias sobre España y el coronavirus. Es en Estados Unidos en donde más publicaciones se detectan al respecto, con mucha diferencia sobre los demás países, fundamentalmente por la cobertura de The New York times, cuyo buscador ha identificado un total

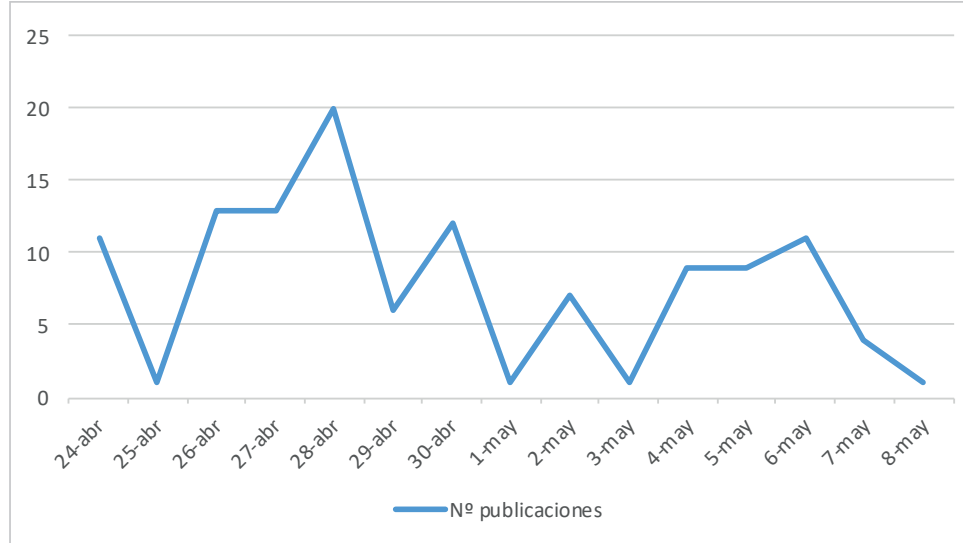

Gráfico 6. Número de noticias por día en la prensa internacional. de 303 noticias con estos parámetros. 
Esta gran diferencia en cuanto al número de noticias publicadas se pone aún más de manifiesto si, a mayores del país, se observan los datos por publicaciones, ya que a excepción de The New York times, el resto de medios oscila entre las 128 noticias de Le figaro y las 6 de Le monde, ambos en Francia.

Estos datos deben ser contextualizados para poder ser comprendidos correctamente, puesto que algunas de las noticias publicadas hacen referencia a la búsqueda "España + Covid" de forma únicamente tangencial. Se trata por ejemplo de las noticias en las que se habla del número de casos de la enfermedad en los países, informes sanitarios comparativos entre estados, sin hacer hincapié en España, datos sobre nuevas políticas a implantar al respecto en la Eurozona o incluso noticias de tipo social y sobre todo deportivo, caso de los clubs de fútbol que hacen test de coronavirus a sus jugadores. Este tipo de noticias han sido clasificadas como neutrales, por no aportar un contenido más allá del meramente objetivo a la noticia en cuestión y, en la mayor parte de los casos, simplemente se trata de nombrar el país en un listado.

Inicialmente se observa una escasa diferencia de peso entre las noticias positivas y las negativas, tanto en términos absolutos, como en la comparación desagregada por países, tal y como queda de manifiesto en el gráfico 8.

Tal y como se observa, en general, las noticias negativas prevalecen sobre las positivas, aunque sin gran diferencia entre ambas, salvo en el caso de Bélgica, con una clara inclinación a la información desfavorable. Las únicas excepciones son Italia, que junto con España fue el país europeo más afectado inicialmente por la pandemia, y Alemania, en los que la visión positiva se sitúa levemente por encima de la negativa.

Al profundizar en los contenidos, aun diferenciando entre noticias positivas y negativas, se observa una clara diferencia entre ambos casos: la prensa internacional refleja una mayor preocupación por la situación económica del país frente a otros aspectos como la propia situación sanitaria o social. Resulta interesante también identificar la preocupación por las consecuencias del coronavirus para el turismo en España, especialmente en el caso de los países del norte de Europa (Bélgica, Alemania y Reino Unido) en donde este tipo de noticias se presentan como contenido negativo, ya que España es uno de sus principales destinos turísticos y la prensa entiende que no estará operativa para el verano.

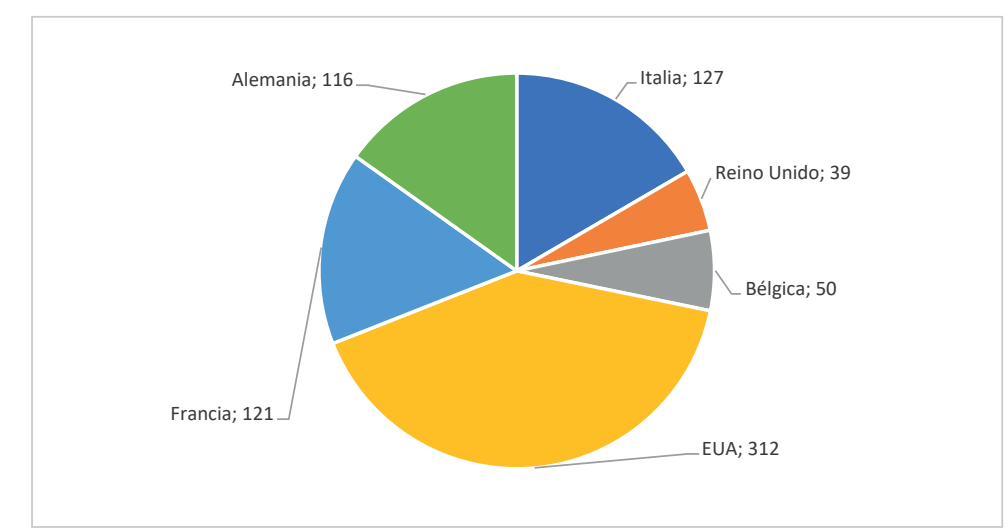

Gráfico 7. Número de noticias por país de publicación.

Tabla 7. Número de noticias publicadas por medio analizado.

\begin{tabular}{|l|l|c|}
\hline \multicolumn{1}{|c|}{ País } & \multicolumn{1}{c|}{ Periódico } & $\begin{array}{c}\text { No de noticias } \\
\text { (España + Covid) }\end{array}$ \\
\hline Francia & Le monde & 6 \\
\hline Francia & Le figaro & 128 \\
\hline Reino Unido & The times & 21 \\
\hline Reino Unido & The daily telegraph & 18 \\
\hline Alemania & Frankfurter allgemeine zeitung & 17 \\
\hline Alemania & Süddeutsche zeitung & 97 \\
\hline Italia & Corriere della sera & 59 \\
\hline Italia & La repubblica & 78 \\
\hline EUA & The Washington post & 9 \\
\hline EUA & The New York times & 303 \\
\hline Bélgica & Nieuwsblad & 14 \\
\hline Bélgica & Het laatste nieuws & 36 \\
\hline
\end{tabular}

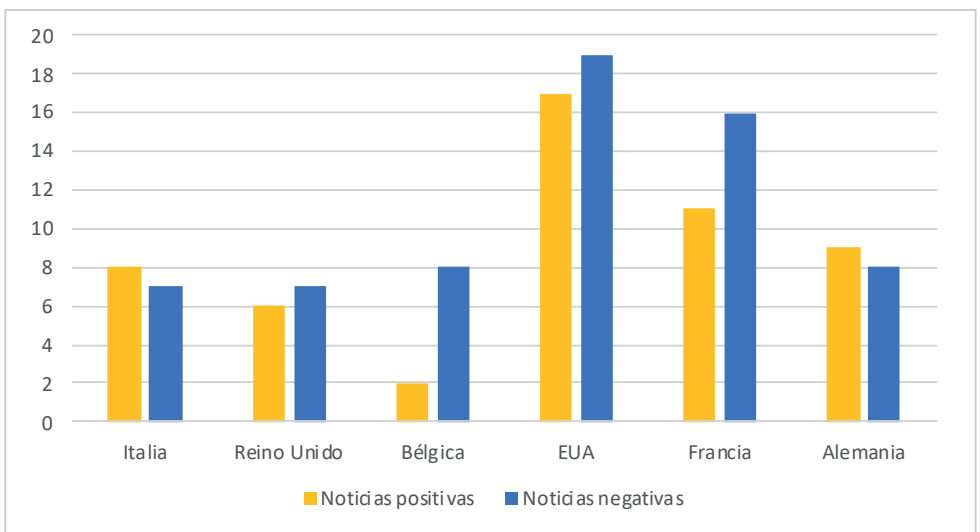

Gráfico 8. Clasificación de las noticias publicadas, según países y contenido positivo o negativo.

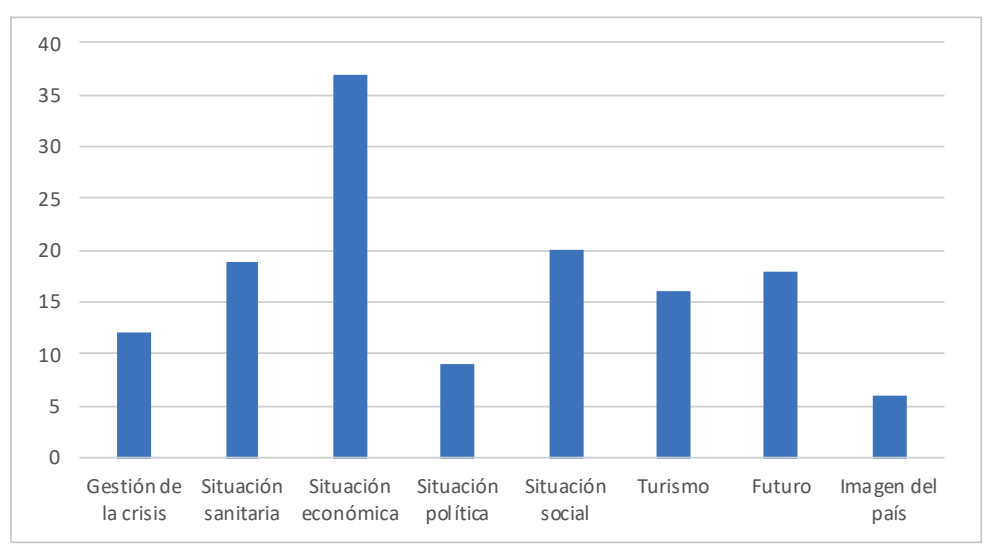

Gráfico 9. Temas abordados en las noticias de carácter negativo. 
Al analizar las noticias positivas, la tendencia es totalmente distinta: si en el grupo de noticias clasificadas como negativas predomina la preocupación por la situación económica, en las positivas predominan los contenidos relacionados con la propia gestión de la crisis y la situación sanitaria o social; el turismo prácticamente no aparece.

Finalmente, se ha analizado quiénes son los protagonistas de las noticias, independientemente de su carácter negativo o positivo. En este caso se observa que la prensa internacional da un peso especial a las noticias centradas en la ciudadanía en general, sin

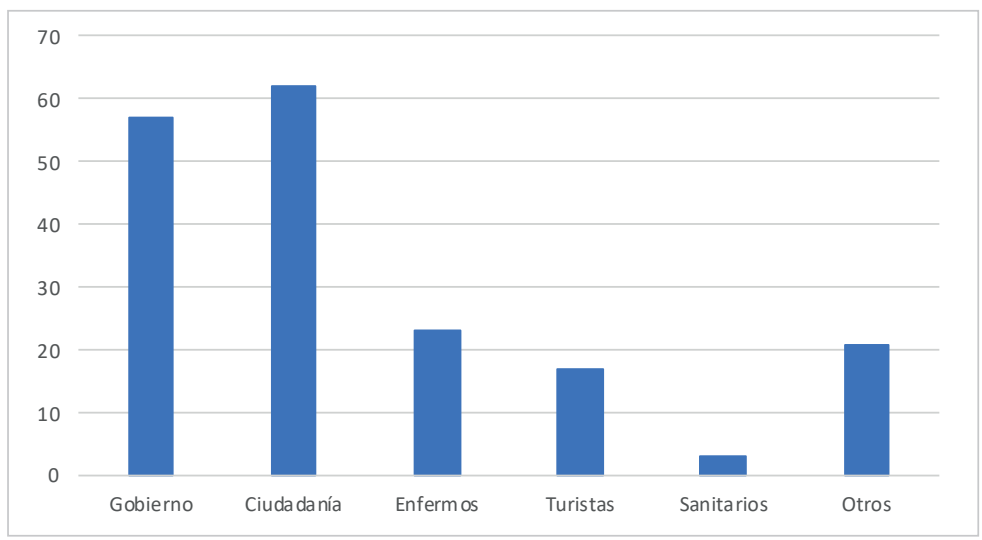

Gráfico 10. Protagonistas de las noticias publicadas. hacer hincapié en el aspecto sanitario ni en los enfermos, además de en el Gobierno. Destaca, como se apuntaba anteriormente, el peso que se da al turismo, acorde al liderazgo mundial que España ejerce en el sector, siendo uno de los destinos preferidos para los ciudadanos de la mayoría de los países abordados en este estudio.

Resulta llamativo por otra parte, el hecho de que sólo se haya identificado una noticia centrada en el personal sanitario, frente al indudable peso que este contenido tiene en la prensa nacional y en la propia comunicación del Gobierno de España.

Finalmente, destaca en presencia también un grupo de noticias, clasificado como "otros" en el gráfico 10, que recoge especialmente las declaraciones de deportistas, principalmente futbolistas, pilotos de fórmula 1 y tenistas, por este orden.

\section{Conclusiones}

La estrategia de comunicación del Gobierno se ha centrado en dos de los principales exponentes de toda situación de crisis como son ser caudal informativo para los medios con presencia constante y la traslación de información de servicio público sobre el impacto de la pandemia, las decisiones adoptadas y normas de higiene y comportamiento social. Se opta por una clara estrategia de relaciones públicas, trabajando la imagen favorable de modo indirecto o implícito, a través de la información y la transparencia en la gestión, entendida esta como la rendición pública de cuentas a través de sucesivas ruedas de prensa. Dichas ruedas de prensa no han estado exentas de polémica por la imposibilidad inicial de los periodistas de preguntar directamente a los comparecientes y verse obligados a hacerlo en diferido por WhatsApp, con el filtrado previo del Secretario de estado de Comunicación, que era quien finalmente formulaba las preguntas de modo oral. En todo caso, en redes sociales el predominio de la comunicación administrativa o de servicio es absoluto, algo que parece coherente con la situación excepcional que se vive durante estas semanas y la demanda creciente de información fiable por parte de la ciudadanía. No obstante, una publicación residual, netamente publicitaria, con la campaña genérica del Gobierno titulada Este virus lo paramos unidos, logra ser la segunda con más likes en Twitter.

La estrategia comunicativa del Gobierno se ha centrado preferentemente en discursos dirigidos a la ciudadanía y en el suministro de información a los medios de comunicación mediante ruedas de prensa diarias de personal técnico, ministros y del presidente del Gobierno. Estas acciones cumplen una doble función:

- suministrar datos e informaciones sobre las decisiones gubernamentales;

- responder a las preguntas de los periodistas.

Para ello, se organizaron 71 ruedas de prensa protagonizadas por el presidente del Gobierno (13) y por ministros (58). Los discursos contaban con una redacción previa en la que primaban determinados mensajes y temáticas centradas en la descripción de una situación bélica (conflicto-guerra-enemigo-armas), que demandaba la unión de todo el país a través del liderazgo del Gobierno, para adoptar decisiones basadas en las recomendaciones de los expertos, con implicaciones mundiales e históricas (catástrofe humanitaria, lo más graves desde la II Guerra Mundial, etc.). Una frase pronunciada en la rueda de prensa del 12 de abril resume muy claramente la idea de guerra como una de las líneas principales del discurso del Gobierno:

“Hoy, los españoles, como el resto de la humanidad, hacemos frente común a un enemigo formidable, un enemigo mortal que ha invadido nuestras ciudades, nuestros pueblos, poniendo en peligro nuestras vidas, nuestra salud, nuestra economía. En definitiva, nuestra manera de vivir. Los campos de batalla allí donde se vive con crudeza toda la crueldad de nuestro enemigo están en los hospitales" (12 abril).

Esta estrategia centrada en los medios de comunicación se basa en la búsqueda de un objetivo claro, combatir a través de ellos la infodemia, en su condición de actores privilegiados del sistema comunicativo del Gobierno, a los que recurre la ciudadanía en la búsqueda de información (Casero-Ripollés, 2020). Sin embargo, existen otros múltiples públicos (ciudadanos, pacientes, familiares, otros países, sanitarios, etc.) con los que se deben llevar a cabo acciones de comunicación específicas, pues la centralidad mediática se ve limitada por las propias características de los medios de comuni- 
cación, confiriéndoles el papel de actores políticos (Borrat, 1989), con sus jerarquizaciones y los procesos de inclusión/ exclusión de temáticas y protagonistas. De ahí que sea imprescindible generar espacios comunicativos diferenciados con esos públicos a partir de sus propias características en el proceso, acceso y decodificación de la información.

En este sentido, comunicar mucho y de manera permanente no implica una mejor información si no va acompañada de datos contrastados y fiables que aporten transparencia a la ciudadanía, a través de medios de comunicación periodísticos, pero también con otros canales y públicos que tienen intereses específicos y características que deben ser conocidas por los responsables de comunicación, lo que les ayudará a mejorar la información y gestionar adecuadamente las relaciones con esos públicos. Así, algunos estudios como el del Reuters Institute (2020) señalan ya que el Gobierno en España no ha desempeñado un papel correcto para ayudar a comprender la pandemia a los ciudadanos. Hubiera sido más adecuado una mejor segmentación de los públicos que sin olvidar el papel difusor de los medios de comunicación, gestionara a los diferentes públicos con estrategias y acciones específicas dirigidas especialmente a ellos, como ha sido el ejemplo del acto organizado a responder a preguntas de niños (La infancia pregunta). Sin embargo, ha sido una excepción y se han obviado otras acciones dirigidas a colectivos de mayores y jóvenes, entre otros.

Siguiendo lo indicado en los manuales de situaciones de crisis, uno de los principales actores en los que se fundamenta la acción comunicativa del Gobierno son los expertos. Por ello, en todas las comparecencias públicas han sido continuas las referencias a las recomendaciones de los científicos y técnicos, dado que estos cuentan con gran prestigio social y coadyuvan a que las decisiones gubernamentales obtengan credibilidad social.

En relación con la comunicación en redes sociales, junto con la divergencia de intereses entre ciudadanía y Gobierno, entre los contenidos más valorados por ella y los más potenciados por él, es reseñable una disonancia entre la estrategia comunicativa del Gobierno en redes y en las ruedas de prensa. Los bulos o fake news sobre el coronavirus y su gestión formaron parte destacada y central del mensaje del Ejecutivo, principalmente del presidente, en sus comparecencias públicas, sobre todo en las primeras semanas, advirtiendo a la población del peligro de compartir información falsa y apelando a que sólo se recurriese a fuentes oficiales y fiables, pero ese contenido apenas tiene presencia en la información publicada en Twitter y Facebook, principal medio de difusión de las fake news. Por otra parte, frente a las fuentes de los gobiernos, los medios de comunicación han desplegado sus propios recursos de investigación para contrastar las informaciones ofrecidas por el propio ejecutivo, ya sea mediante la protesta por no poder preguntar de manera directa en las ruedas de prensa, con informaciones en sus medios o por la imposibilidad de repreguntar en las comparecencias públicas.

El país donde más se ha publicado sobre España y la Covid-19 ha sido EUA, según los datos ofrecidos por los buscadores de la propia prensa analizada; le siguen Italia y Francia.

Hay bastante equilibrio entre las noticias clasificadas como positivas y las negativas, aunque se puede identificar una diferencia mínima a favor de las negativas. En éstas, suelen prevalecer las noticias económicas (crisis derivada de la sanitaria, índices de paro, empresas que cierran, ertes, malas previsiones para el turismo en un futuro próximo, etc.), seguidas de aquellas con un carácter más social y sanitario, fundamentalmente noticias sobre la desescalada del confinamiento.

El peso informativo de las noticias clasificadas como positivas recae sobre la gestión de la crisis del coronavirus en sí, alivio progresivo del confinamiento, normativas gubernamentales al respecto, etc., seguido de las informaciones del ámbito sanitario y social.

En cuanto a los protagonistas, las noticias internacionales sobre España se centran fundamentalmente en el Gobierno como gestor de la crisis (medidas que se adoptan, anuncios en ruedas de prensa, decisiones técnicas, etc.) y en los ciudadanos (testimonios personales, noticias sobre el desconfinamiento progresivo por grupos de edad, etc.).

En relación con los temas, destaca el número de noticias sobre turismo y la preocupación sobre esta materia, sobre todo en la prensa del Norte de Europa, belga, alemana e inglesa.

Facebook y Twitter, especialmente esta última desde el punto de vista del volumen total de publicaciones, son las redes sociales de referencia del Gobierno de España a la hora de desplegar la estrategia comunicativa online sobre la gestión de la crisis del coronavirus Covid-19. Aunque guardan similitudes entre ellas, pueden señalarse también notables diferencias, tanto desde el punto de vista de la intensidad de uso, como de los contenidos y aspectos formales de las respectivas publicaciones.

En Twitter, con un uso mucho más intenso que Facebook, predominan los contenidos informativos, hecho que parece responder al uso, en general, más apropiado de esta red para la información o la actualidad y particularmente para la comunicación política, que señalan diversos estudios, derivado probablemente de su inmediatez y su consumo más abierto que el de otras plataformas. En Facebook, también relacionado con la información y la actualidad y contando igualmente con un peso significativo de los anteriores contenidos, predominan las publicaciones sobre las ruedas de prensa del Gobierno, también presentes en Twitter, pero con menor importancia relativa, ya que en esta red se difunden muchos más contenidos que en Facebook.

Ese uso más intensivo de Twitter, con publicaciones específicas de esta red, no difundidas en Facebook u otras plataformas del Gobierno de España, explica los picos de actividad general que se observan coincidiendo con las fechas de cele- 
bración del Consejo de Ministros en los que se aprueban medidas o se toman decisiones especialmente trascendentales que merecen explicación pública y más detallada. En Facebook, donde la actividad fundamental consiste en retransmitir ruedas de prensa, que en esta situación son diarias, la intensidad de publicaciones en más regular.

En todo caso, en una y otra plataforma se observa una tendencia decreciente desde el inicio del estado de alarma hasta el final del estudio, tanto en el volumen de publicaciones como en la interacción de los usuarios con las mismas, que parece responder a la normalización de la situación social y, por tanto comunicativa, transitando de un momento de crisis inicial, con la adopción y explicación de medidas drásticas, a la asunción de la denominada "nueva normalidad" por parte de la ciudadanía y a un mayor control de la situación general por parte del Gobierno. A medida que ocurre esto, también se estandariza el patrón de publicaciones en ambas redes, que sigue un esquema prácticamente idéntico, diferente entre ellas, jornada tras jornada.

Twitter es, como se ha señalado, la red más usada por el Gobierno, pero Facebook genera más interacción, tanto en números absolutos como sobre todo relativos; con tres veces menos seguidores supera a Twitter en todos los parámetros de interacción analizados: likes, comentarios y contenidos compartidos.

Al margen de la mayor intensidad de uso de Twitter derivada de la publicación de contenidos específicos para esta red, se observa una alta correlación de contenidos entre ella y Facebook, ya que prácticamente todo lo publicado en Facebook está en Twitter, salvo una rueda de prensa de transcendencia menor. Por tanto, pese a lo que pudiese deducirse inicialmente de un análisis puramente cuantitativo, no debe concluirse que exista una estrategia o uso diferenciado en una red y otra, más allá de las variaciones de datos derivadas de un mayor volumen de publicaciones en Twitter. No se aprovechan, en definitiva, las potencialidades de cada una de las redes ni se generan contenidos adaptados a los diferentes públicos, a excepción de los clips de vídeo posteriores a las ruedas de prensa, muy característicos de la estrategia en Twitter, aunque también incluidos muy puntualmente en Facebook.

En relación con el vídeo, cabe señalar su gran importancia en las publicaciones del Gobierno de España en redes, presente casi en la mitad de los tweets y mayoritario en las publicaciones de Facebook. Junto con el intenso uso de las imágenes estáticas o animadas, mayoritarias en Twitter, ello lleva a concluir que la multimedialidad, como cabría esperar, rige la estrategia comunicativa del Ejecutivo en redes sociales. Los datos de interacción, una vez más, lo avalan, pues cualquiera de las publicaciones con mayor éxito incluye recursos de este tipo; enriquecidas además en numerosas ocasiones con enlaces a páginas externas que permiten ampliar la información.

Se constata que las ruedas de prensa constituyen el contenido fundamental de Facebook y uno de los más importantes de Twitter, al nivel de la información administrativa o de servicio. Pese a su mayor peso en Facebook, Twitter las rentabiliza en mayor medida, ya que no se limita a la emisión íntegra, sino que realiza extractos y otras publicaciones derivadas con contenidos específicos, que generan un alto impacto; por ello, sin ser el contenido mayoritario en Twitter, las ruedas de prensa sí son los contenidos más comentados y están entre los más compartidos y con mayor número de likes. En Facebook todas las publicaciones con más interacciones son ruedas de prensa. Se concluye por tanto que, al margen de su peso en relación con el volumen total de publicaciones, las comparecencias públicas de los cargos del Gobierno poseen una alta capacidad de engagement con la ciudadanía.

En este sentido, merecen especial mención las ruedas de prensa de los sábados del presidente del Gobierno, que desde el inicio del estado de alarma se suceden regularmente cada semana en horario de prime time, formando parte, por tanto, de una estrategia de comunicación claramente planificada. Son precisamente estas comparecencias las que acumulan el mayor número de comentarios, likes y veces compartidas y no otras, como las de Fernando Simón, director del Centro de Coordinación de Alertas y Emergencias Sanitarias del Ministerio de Sanidad, que aporta información tan valiosa como los datos diarios de evolución de la enfermedad, o las del propio ministro de Sanidad, o, incluso las del presidente en jornadas diferentes al sábado.

Desde el punto de vista de los intereses compartidos o el interés público, de la investigación se desprende una divergencia clara entre el interés del Gobierno y de la ciudadanía, que concentra sus interacciones en días y publicaciones que no son las más potenciadas por el Ejecutivo en su estrategia. En cuanto a los contenidos digitales, es cierto que ambos coinciden en el valor de las ruedas de prensa, pero las más compartidas o comentadas y las que más likes acumulan no son las de los días con mayor volumen de información ni las más destacadas en cuanto a la elaboración de clips o materiales secundarios por parte del Gobierno; destacando las del presidente, como ya se ha visto, en detrimento de otras más técnicas o específicas.

Finalmente, aunque no forman parte de la investigación, por no considerarse estrictamente redes sociales al uso, cabe indicar que en futuros trabajos resultará interesante analizar la comunicación del Gobierno en relación con este asunto en WhatsApp y Telegram. Concretamente en el denominado Hispabot-Covid19 de WhatsApp, un canal de consulta automático que se sirve de un asistente conversacional para responder a preguntas que sobre el coronavirus planteen los usuarios y en el canal del Ministerio de Sanidad en Telegram, que suma 338.728 suscriptores (11/05/2020) y es usado por el Gobierno para difundir a diario los datos de evolución de la enfermad, junto con contenidos de todo tipo de información administrativa y de servicio principalmente, pero también campañas específicas y otros materiales. 


\section{Referencias}

$A B C$ (2020). "Cientos de periodistas rechazan el control de las preguntas en las ruedas de prensa en La Moncloa". $A B C$, 6 abril.

https://www.abc.es/espana/abci-medio-centenar-periodistas-rechazan-control-preguntas-ruedas-prensamoncloa-202003312101_noticia.html

Almansa-Martínez, Ana (2008). "Estudio sobre el uso de las nuevas tecnologías en comunicación institucional”. Icono 14, v. 6, n. 2, pp. 1-14.

https://doi.org/10.7195/ri14.v6i2.349

Almansa-Martínez, Ana; Fernández-Torres, María-Jesús (2011). “Estudios sobre la comunicación digital de las organizaciones sociales en España”. Vivat academia. Revista de comunicación, n. 117, pp. 337-252.

https://doi.org/10.15178/va.2011.117E.337-352

Borge-Bravo, Rosa; Esteve-del-Valle, Marc (2020). "Twitter como espacio de transformación y debate político". El país, 16 enero.

http://agendapublica.elpais.com/twitter-como-espacio-de-transformacion-y-debate-politico

Borrat, Héctor (1989). El periódico, actor político. Barcelona: Gustavo Gili. ISBN: 9788425213953

Casero-Ripollés, Andreu (2020). "Impact of Covid-19 on the media system. Communicative and democratic consequences of news consumption during the outbreak". El profesional de la información, v. 29, n. 2, e290223.

https://doi.org/10.3145/epi.2020.mar.23

Cinelli, Matteo; Quattrociocchi, Walter; Galeazzi, Alessandro; Valensise, Carlo-Michele; Brugnoli, Emanuele; Schmidt, Ana-Lucia; Zola, Paola; Zollo, Fabiana; Scala, Antonio (2020). "The covid-19 social media infodemic". arXiv preprint arXiv:2003.05004.

https://arxiv.org/pdf/2003.05004.pdf

España (2020). “Real decreto 463/2020, de 14 de marzo, por el que se declara el estado de alarma para la gestión de la situación de crisis sanitaria ocasionada por el Covid-19". BOE, n. 67, 14 marzo.

https://www.boe.es/diario_boe/txt.php?id=BOE-A-2020-3692

Fernández-Souto, Ana-Belén; Vázquez-Gestal, Montse; Corbacho-Valencia, Juan-Manuel (2016). "La reputación de España en Europa como eje central en la planificación de la imagen de marca país: el caso de Alemania, Francia y Gran Bretaña". Punto cero, v. 21, n. 33, pp. 25-34.

https://www.redalyc.org/articulo.oa?id=421849365003

Fontrodona, Joan; Muller, Philip (2020). "Reforzar la integridad empresarial ante la crisis del Covid-19". SSRN, 8 abril. https://doi.org/10.2139/ssrn.3571706

Galán-Galán, Alfredo (2000). “La comunicación pública”. En: Tornos-Mas, Joaquín; Galán-Galán, Alfredo. Comunicación pública: La información administrativa al ciudadano. Madrid: Marcial Pons Ediciones Jurídicas y Sociales, pp. 21-145. ISBN: 8472488241

Gil-Ramírez, Marta; Gómez-De-Travesedo-Rojas, Ruth; Almansa-Martínez, Ana (2019). "Politainment y personalización política. ¿De la televisión a YouTube?”. Revista latina de comunicación social, n. 74, pp. 1542-1564.

https://doi.org/10.4185/RLCS-2019-1398

Huynh, Toan-Luu-Duc (2020). "The Covid-19 risk perception: A survey on socioeconomics and media attention". Economics bulletin, v. 40, n. 1, pp. 758-764.

https://ideas.repec.org/a/ebl/ecbull/eb-20-00175.html

IAB Spain (2019). Estudio anual de redes sociales 2019.

https://iabspain.es/estudio/estudio-anual-de-redes-sociales-2019

Krippendorff, Klaus (1990). Metodología de análisis de contenido. Teoría y práctica. Barcelona: Paidós Ibérica. ISBN: 84 75096271

Mancero, Julio-Bravo; Larrea-Naranjo, Carlos; Ruales-Parreño, Ramiro (2020). "Tratamiento del Covid-19, Ecuador mediante el humor periodístico". Brazilian journal of health review, v. 3, n. 2, pp. 3523-3541.

https://doi.org/10.34119/bjhrv3n2-183

Más-Manchón, Lluís; Guerrero-Solé, Frederic (2019). "The use of hashtags as a political branding strategy". Revista internacional de relaciones públicas, v. 9, n. 17, pp. 5-24.

https://doi.org/10.5783/RIRP-17-2019-02-05-24 
Mejía, Christian R.; Rodríguez-Alarcón, J. Franco; Garay-Ríos, Lizet; Enríquez-Anco, María-de-Guadalupe; Moreno, Alfrando; Huaytan-Rojas, Kennedy; Huancahuari-Ñañacc-Huari, Nory; Julca-Gonzales, Ángel; Álvarez, Christian H.; Choque-Vargas, José; Curioso, Walter H. (2020). "Percepción de miedo o exageración que transmiten los medios de comunicación en la población peruana durante la pandemia de la Covid-19". Revista cubana de investigaciones biomédicas, v. 39, n. 2, pp. 1-20.

http://www.revibiomedica.sld.cu/index.php/ibi/article/view/698

Názaro, Andrea; Crozzoli, Fabrizio; Álvarez-Nobell, Alejandro (2019). “Comunicación política digital en Instagram. Los casos de Cristina Fernández de Kirchner y Mauricio Macri en Argentina". Revista internacional de relaciones públicas, v. 9, n. 18, pp. 5-28.

https://doi.org/10.5783/RIRP-18-2019-02-05-28

Nielsen, Rasmus-Kleis; Fletcher, Richard; Newman, Nic; Brennen, J. Scott; Howard, Philip (2020). Navigating the 'infodemic': How people in six countries access and rate news and information about coronavirus. Reuters Institute for the Study of Journalism, University of Oxford.

https://reutersinstitute.politics.ox.ac.uk/navegando-la-infodemia-asi-consume-noticias-e-informacion-sobrecoronavirus-espana-argentina-otros-paises

OMS (2020). Novel coronavirus (2019-nCoV) Situation report - 13.

https://www.who.int/docs/default-source/coronaviruse/situation-reports/20200202-sitrep-13-ncov-v3.pdf

RTVE (2020). "Más de trescientos periodistas reclaman a La Moncloa poder preguntar con libertad y sin filtro previo". RTVE.es, 1 abril.

https://www.rtve.es/noticias/20200401/mas-trescientos-periodistas-reclaman-moncloa-poder-preguntar-libertad-sinfiltro-previo/2011216.shtml

Salerno, Antonella (2000). “La comunicación institucional o comunicación imagen”. En: Tornos-Mas, Joaquín; Galán-Galán, Alfredo. Comunicación pública: La información administrativa al ciudadano. Madrid: Marcial Pons Ediciones Jurídicas y Sociales, pp. 173-211. ISBN: 8472488241

Sartori, Giovanni (1998). Homo videns. La sociedad teledirigida. Madrid: Taurus. ISBN: 950511429X

Soengas-Pérez, Xosé; Elías-Pérez, Carlos; López-Cepeda, Ana-María (2018): “El tratamiento de la información política e institucional en TVE". Revista latina de comunicación social, n. 73, pp. 1072-1089.

https://doi.org/10.4185/RLCS-2018-1297

Ubillos-Landa, Silvia; González-Castro, José-Luis; Puente-Martínez, Alicia; Gracia-Leiva, Marcela (2020). Afrontando el impacto del Covid-19: resultados preliminares I. Universidad de Burgos.

https://riubu.ubu.es/bitstream/handle/10259/5279/Afrontando_el_impacto_del_COVID19-1.pdf

Wimmer, Roger D.; Dominick, Joseph R. (2006). Mass media research: An introduction. Wadsworth: Thomson. ISBN: 0534647189

Wilcox, Dennis L.; Ault, Phillip H.; Agee, Warren K.; Cameron, Glen T. (2001). Relaciones públicas. Estrategias y tácticas. Madrid: Addison Wesley. ISBN: 8478290419

Xifra, Jordi (2020). “Comunicación corporativa, relaciones públicas y gestión del riesgo reputacional en tiempos del Covid-19". El profesional de la información, v. 29, n. 2, e290220.

https://doi.org/10.3145/epi.2020.mar.20

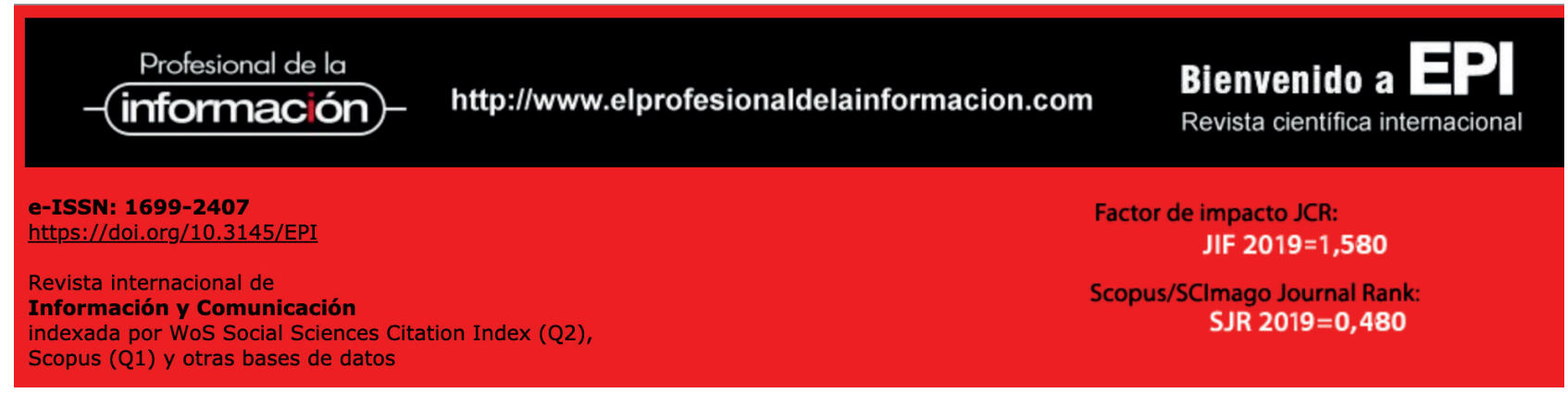

